\title{
Simple Quadratic Interpolation-Inspired Symbiosis Organisms Search Algorithm for Optimal Placement of Capacitors in Radial Distribution Networks with Different Loading Models
}

\author{
Tri Phuoc Nguyen, ${ }^{1}$ Tuan Trong Nguyen, ${ }^{2}$ Trung Hieu Quang, ${ }^{3}$ and Dieu Ngoc Vo $\mathbb{D D}^{1,4}$ \\ ${ }^{1}$ Department of Power Systems, Ho Chi Minh City University of Technology (HCMUT), 268 Ly Thuong Kiet Street, District 10, \\ Ho Chi Minh City, Vietnam \\ ${ }^{2}$ Southern Electrical Testing Company, Southern Power Corporation, Electricity of Vietnam, 22 Bis Phan Dang Luu Street, \\ District Binh Thanh, Ho Chi Minh City, Vietnam \\ ${ }^{3}$ Southern Region Load Dispatch Center, National Load Dispatch Center, Electricity of Vietnam, 5 Su Thien Chieu Street, \\ District 3, Ho Chi Minh City, Vietnam \\ ${ }^{4}$ Vietnam National University Ho Chi Minh City, Linh Trung Ward, Thu Duc District, Ho Chi Minh City, Vietnam
}

Correspondence should be addressed to Dieu Ngoc Vo; vndieu@gmail.com

Received 4 March 2020; Revised 18 July 2020; Accepted 30 July 2020; Published 30 September 2020

Academic Editor: Mohammad Hassan Khooban

Copyright (C) 2020 Tri Phuoc Nguyen et al. This is an open access article distributed under the Creative Commons Attribution License, which permits unrestricted use, distribution, and reproduction in any medium, provided the original work is properly cited.

\begin{abstract}
This paper proposes a novel hybrid algorithm based on a combination of the simple quadratic interpolation and the symbiosis organisms search algorithm (SQI-SOS) for finding the optimal location and size of capacitors in radial distribution networks. The objective of the problem is to minimize the system operating cost so that the net yearly savings of the system are increased. The effectiveness of the SQI-SOS has been tested on 33-, 69-, and 119-bus radial distribution networks with different load models. The obtained results from the test system by the proposed SQI-SOS are compared with those from the conventional SOS and other mature optimization methods in the literature. The result comparison has shown that the proposed SQI-SOS algorithm can provide a better solution than the other methods. Accordingly, the proposed SQI-SOS can be a very effective and efficient method for dealing with the optimal capacitor placement problem in distribution networks.
\end{abstract}

\section{Introduction}

The reactive power compensation plays an important role in the operation of power distribution networks since it brings many technical benefits such as decreasing power losses, enhancing voltage profiles, correcting power factor, and releasing system capacity. To acquire such benefits, shunt capacitors are widely employed in distribution networks to inject the reactive power. However, the inappropriate placement of capacitors may result in reducing the benefits of the system and even risking the whole system operation. Therefore, it is very important to determine the optimal location and size of capacitors to be installed in distribution networks so that the maximum benefits of the system can be acquired while satisfying all the operating constraints of the system.

In the recent past decades, the optimal capacitor placement (OCP) problem has been formulated with many objective functions such as power loss reduction, voltage profile improvement, capacitor installation cost minimization, network stability maximization, and reduction of burden on existing lines [1]. Many techniques have also been developed for dealing with such problems. In general, these techniques can be classified into four main categories including analytical, numerical programming, heuristic, and artificial intelligence methods [2]. Analytical methods have been early applied for the OCP problem, and they are easy to be understood and implemented. However, the analytical 
methods may provide inaccurate solutions since they use continuous variables to model the location and size of capacitors. The obtained results would need to be rounded to achieve practical values. Therefore, the designed system may suffer from overvoltage situation and has more or less power losses than the calculated one [2]. In addition to the analytical approach, numerical programming methods such as dynamic programming (DP) [3], mixed integer linear programming approach (MILP) [4], integer quadratic programming (IQP) [5], clustering-based optimization (CBO) [6], and interior point method (IPM) [7] have been also applied for solving the OCP problem. Although these methods consider the location and size of capacitors as discrete variables, their computational time might take longer than the analytical approaches. In addition, the OCP problem is considered as a nonlinear optimization problem with a nondifferentiable objective function. Therefore, numerical programming methods may not effectively deal with the OCP problem for such cases. On the contrary, the heuristic methods as in [8-10] are intuitive, easy to understand, and simple for implementation. Based on the fast and practical strategies of these methods, they may help to reduce the search space in finding the final solution. However, heuristic methods do not always guarantee to obtain the optimal solution for the OCP problem [2].

In recent years, artificial intelligence- (AI-) based methods have been developed and effectively implemented for dealing with the OCP problem. A survey of studies from the literature has shown that the OCP problem has been successfully solved by the genetic algorithm (GA) [11-13], tabu search (TS) [14], particle swarm optimization (PSO) [15], cuckoo search algorithm (CSA) [16], improved harmony algorithm (IHA) [17], flower pollination algorithm (FPA) [18], artificial bee colony (ABC) [19], teaching learning-based optimization (TLBO) [20], hybrid differential evolution and pattern search (DE-PS) [21], plant growth simulation algorithm (PGSA) [22], crow search algorithm (CSA) [23], whale optimization algorithm (WOA) [24], Limaçon inspired spider monkey optimization (LSMO) [25], multiswarm particle swarm optimization (MSPSO) [26], penalty-free genetic algorithm (PFGA) [27], competitive swarm optimizer (CSO) [28], grasshopper optimization algorithm (GOA) [29], and modified Gbest-guided Artificial Bee Colony (MGABC) [30]. Although AI-based methods show that they have a performance improvement in solving the OCP problem, they may not guarantee to obtain the optimal solution for complex and large-scale problems. Moreover, some of them may suffer from local optima and require a long computational time. Therefore, there is always a need to develop and introduce new techniques for effectively solving the OCP problem.

Symbiotic organisms search (SOS) is new a populationbased algorithm proposed by Cheng and Prayogo [31] in 2014. This algorithm is inspired from symbiotic relationships among species in nature. The SOS method was first applied for various highly nonlinear benchmark functions and some other engineering optimization problems, and it is reported that the SOS has outperformed some other popular optimization methods such as GA, PSO, and DE in solving such problems [31]. Since the SOS is relatively a new algorithm, it needs to be further explored and investigated. To improve the performance of the SOS, Nama et al. [32] have proposed a hybrid symbiosis organisms search algorithm by embedding the simple quadratic interpolation (SQI) to enhance exploration ability of SOS in the search space; thus, it can efficiently improve the convergence characteristic of the algorithm. Therefore, the robustness of the SQI-SOS is increased by the combination of SQI and SOS in the exploration capability. In this paper, the SQI-SOS is proposed to determine the optimal location and size of capacitors in radial distribution networks with the objective of total operating cost reduction. The proposed SQI-SOS has been tested on 33-bus, 69-bus, and 119-bus radial distribution networks with different load models. The results obtained by the SQI-SOS are compared with the results obtained from the conventional SOS and other methods such as CSA, IHA, $\mathrm{FPA}, \mathrm{ABC}$, and MGABC.

The current paper contains the main contributions as follows:

(i) Firstly, we propose a novel hybrid method via the combination of SQI and SOS (SQI-SOS) to estimate the optimal siting and sizing of capacitors for the first time, in which the overall cost objective function is minimized.

(ii) Secondly, we introduce a new initialization process for treating discrete capacitor sizing variables. Based on this initialization method, only a few adjustments are required in the original solution method.

(iii) Thirdly, this is the first time in this study where both continuous and discrete capacitor sizes have been investigated for a result comparison.

(iv) Fourthly, the actual voltage-dependent nonlinear load models have been utilized for investigations.

(v) Finally, the proposed SQI-SOS method offers the solutions with a better quality than those acquired by the previously reported methods in the comparative cases.

The remaining of this paper is organized as follows: Section 2 provides the mathematical formulation of the OCP problem. Sections 3 and 4 represent the SQI-SOS algorithm and its implementation to the OCP problem. The numerical results are reported in Section 5. Finally, the paper is concluded in Section 6.

\section{Problem Formulation}

2.1. Objective Function. In this study, the optimization problem of the OCP is formulated with an objective of minimizing the system operating cost which is described by the following equation [16]:

$$
\operatorname{cost}=\operatorname{Min}\left\{K_{P} \cdot \sum_{i=1}^{L} P_{\mathrm{loss}, i} \cdot T_{i}+K_{C} \cdot \sum_{j=1}^{\mathrm{CB}} Q_{C, j}+\left(K_{c i}+K_{o}\right) \cdot \mathrm{CB}\right\} .
$$


In order to analyze the OCP problem with an actual voltage-dependent load model, the original objective function can be modified as follows (MC):

$$
\mathrm{MC}=\operatorname{Min}\left\{K_{P} \cdot P_{\mathrm{loss}} \cdot T+K_{C} \cdot \sum_{j=1}^{\mathrm{CB}} Q_{C, j}+\left(K_{c i}+K_{o}\right) \cdot \mathrm{CB}\right\},
$$

subject to following constraints.

\subsection{Constraint}

(i) Real and reactive power balance constraint:

$$
\begin{array}{r}
P_{\text {slack }}=\sum_{i=1}^{n_{l}} P_{D, i}+\sum_{j=1}^{n_{b r}} P_{L, j}, \\
Q_{\text {slack }}+\sum_{i=1}^{\mathrm{CB}} Q_{C, i}=\sum_{i=1}^{n_{l}} Q_{D, i}+\sum_{j=1}^{n_{b r}} Q_{L, j} .
\end{array}
$$

(ii) Voltage limits at buses:

$$
V_{i, \min } \leq V_{i} \leq V_{i, \max } ; \quad i=1, \ldots, N_{b} .
$$

(iii) Maximum real power flow constraint:

$$
\left|\mathrm{PF}_{k}\right|<\mathrm{PF}_{k}^{\max } \text {. }
$$

(iv) Reactive power compensation limits:

$$
Q_{C, j}^{\min } \leq Q_{C, j} \leq Q_{C, j}^{\max } ; \quad j=2, \ldots, C B .
$$

(v) Total reactive power compensation limits:

$$
\sum_{j=1}^{\mathrm{CB}} \mathrm{Q}_{C, j} \leq \sum_{j=1}^{n_{l}} \mathrm{Q}_{D, j}
$$

(vi) Overall system power factor limits:

$$
\mathrm{PF}_{\min } \leq \mathrm{PF}_{\text {overall }} \leq \mathrm{PF}_{\max } \text {. }
$$

2.3. Load Models. In the previous load flow studies, the load models with constant active and reactive powers, i.e., constant loads, were commonly utilized. However, power demands of practical loads highly depend on the network voltage. So, these loads can be modeled as voltage-dependent loads which include residential, industrial, and commercial loads. Mathematically, the voltage-dependent load models can be formulated as [33]

$$
\begin{aligned}
& P_{D, i}=P_{D o, i}\left(\psi_{p 1}\left(\frac{V_{i}}{V_{0}}\right)^{\alpha_{o}}+\psi_{p 2}\left(\frac{V_{i}}{V_{0}}\right)^{\alpha_{i}}+\psi_{p 3}\left(\frac{V_{i}}{V_{0}}\right)^{\alpha_{r}}+\psi_{p 4}\left(\frac{V_{i}}{V_{0}}\right)^{\alpha_{c}}\right), \\
& Q_{D, i}=Q_{D o, i}\left(\psi_{q 1}\left(\frac{V_{i}}{V_{0}}\right)^{\beta_{o}}+\psi_{q 2}\left(\frac{V_{i}}{V_{0}}\right)^{\beta_{i}}+\psi_{q 3}\left(\frac{V_{i}}{V_{0}}\right)^{\beta_{r}}+\psi_{q 4}\left(\frac{V_{i}}{V_{0}}\right)^{\beta_{c}}\right),
\end{aligned}
$$

where $\alpha$ and $\beta$ are the active and reactive power exponents for the different types of load in which subscripts $o, i, r$, and $c$ are, respectively, the constant, industrial, residential, and commercial loads. The exponent values pertaining to the load types are given in Table $1[33,34] .\left\{\psi_{p 1}, \psi_{p 2}, \psi_{p 3}, \psi_{p 4}\right\}$ and $\left\{\psi_{q 1}, \psi_{q 2}, \psi_{q 3}, \psi_{q 4}\right\}$ are active and reactive power weight coefficients, respectively, and these coefficients are chosen based on the weight of the consumed active and reactive power by practical load. The different types of the load model and the practical mixed load model can be defined as follows:

(i) Constant load: $\psi_{p 1}=1, \psi_{p 2}=0, \psi_{p 3}=0, \psi_{p 4}=$ 0 and $\psi_{q 1}=1, \psi_{q 2}=0, \psi_{q 3}=0, \psi_{q 4}=0$

(ii) Industrial load: $\psi_{p 1}=0, \psi_{p 2}=1, \psi_{p 3}=0, \psi_{p 4}=0$ and $\psi_{q 1}=0, \psi_{q 2}=1, \psi_{q 3}=0, \psi_{q 4}=0$

(iii) Residential load: $\psi_{p 1}=0, \psi_{p 2}=0, \psi_{p 3}=1, \psi_{p 4}$ $=0$ and $\psi_{q 1}=0, \psi_{q 2}=0, \psi_{q 3}=1, \psi_{q 4}=0$

(iv) Commercial load: $\psi_{p 3}=0, \psi_{p}=1, \psi_{q 3}=0, \psi_{q 4}=1$

(v) Mixed or practical load: the aggregation of the different load types is implemented by $\psi_{p 1}+\psi_{p 2}+$ $\psi_{p 3}+\psi_{p 4}=1$ and $\psi_{q 1}+\psi_{q 2}+\psi_{q 3}+\psi_{q 4}=1$

To examine the standard radial distribution systems with a practical mixed load model, we assume that these systems only include industrial, residential, and commercial loads as in $[33,34]$. As the constant loads are not included, the coefficients $\psi_{p 1}$ and $\psi_{q 1}$ are equal to 0 . In addition, this study assumes that the active and reactive power consumptions of industrial, residential, and commercial loads are, respectively, $40 \%, 45 \%$, and $15 \%$ of the total load demand, resulting in the setting values of weight factors related to industrial load $\psi_{p 2}=0.4$ and $\psi_{q 2}=0.4$, residential load $\psi_{p 3}=0.45$ and $\psi_{q 3}=0.45$, and commercial load $\psi_{p 4}=0.15$ and $\psi_{q 4}=$ 0.15 .

\section{A Hybrid Symbiosis Organisms Search Algorithm}

3.1. Symbiosis Organisms Search Algorithm. The SOS proposed by Cheng and Prayogo in 2014 [31] is a novel metaheuristic algorithm. This algorithm portrays the symbiotic relationships between two different organisms in an ecosystem. Similar to most population-based algorithms, the SOS starts the search process with a population of organisms (i.e., ecosystem) which is randomly generated. Each organism represents a solution to the considered problem. Based on the population of organisms, the fitness function corresponding to each organism is calculated. In the SOS, there are three phases (i.e., mutualism phase, commensalism phase, and parasitism phase) that mimic symbiotic relationships between two organisms in nature. The new organisms are generated via these phases which are described as follows.

3.1.1. Mutualism Phase. Mutualism is a symbiotic relationship where both organisms get benefits from each other. In the SOS, an organism $X_{j}$ is randomly selected from the 
TABLE 1: Load types and exponent values.

\begin{tabular}{lcccc}
\hline Load type & Constant load & Industrial load & Residential load & Commercial load \\
\hline Exponents & $\alpha_{o}=0 ; \beta_{o}=0$ & $\alpha_{i}=0.18 ; \beta_{i}=6$ & $\alpha_{r}=0.92 ; \beta_{r}=4.04$ & $\alpha_{c}=1.51 ; \beta_{c}=3.4$ \\
\hline
\end{tabular}

ecosystem, which is used to interact with an organism $X_{i}$. The organism $X_{i}$ is the $i$ th member of the ecosystem. Both organisms increase their mutual survival abilities based on a mutualism in the ecosystem. The new organisms for $X_{i}$ and $X_{j}$ are generated based on the mutualistic symbiosis relationship between organisms $X_{i}$ and $X_{j}$ by the following equations [31]:

$$
\begin{aligned}
X_{i}^{\text {new }} & =X_{i}+\operatorname{rand}(0,1) \times\left(X_{\text {best }}-\mathrm{MV} \times b f_{1}\right), \\
X_{j}^{\text {new }} & =X_{j}+\operatorname{rand}(0,1) \times\left(X_{\text {best }}-\mathrm{MV} \times b f_{2}\right), \\
\mathrm{MV} & =\frac{X_{i}+X_{j}}{2},
\end{aligned}
$$

where rand $(0,1)$ is a vector of random numbers between 0 and $1 ; X_{\text {best }}$ represents the best organism in an ecosystem; MV denotes a mutual vector that represents the mutualistic symbiosis relationship between organisms $X_{i}$ and $X_{j} ; b f_{1}$ and $b f_{2}$ are the benefit factors which describe the level of benefit to each organism. These factors are stochastically selected as either 1 or 2 ( 1 is for partial benefit while 2 is for full benefit).

The new organisms are accepted only if they give a better fitness value compared to the previous organisms.

3.1.2. Commensalism Phase. Commensalism is a symbiotic relationship where one organism is benefited and the other is neither harmed nor benefited. In this phase, an organism $X_{j}$ is randomly selected from the ecosystem to interact with the organism $X_{i}$. As a result from the interaction, organism $X_{i}$ benefits while the organism $X_{j}$ is neither harmed nor benefited. The new organism of $X_{i}$ produced by this interaction is calculated as follows [31]:

$$
X_{i}^{\text {new }}=X_{i}+\operatorname{rand}(-1,1) \times\left(X_{\text {best }}-X_{j}\right) .
$$

According to the rules, the new organism is only updated if it gives a better fitness value compared to the prior organism.

3.1.3. Parasitism Phase. Parasitism is a symbiotic relationship between two different organisms where one benefits and the other is harmed. In this phase, organism $X_{i}$ is offered a role player of a parasite through a vector called "Parasite_Vector." The organism $X_{i}$ is duplicated and modified itself by using a random number to create a Parasite_Vector in the search space. Another organism $X_{j}$ is randomly chosen and serves as a host to the Parasite_Vector. If the Parasite_Vector has a better fitness value, then it will kill organism $X_{j}$ and replace it in the ecosystem. Otherwise, organism $X_{j}$ will have immunity from the parasite, and the Parasite_Vector will disappear from that ecosystem [31].

3.2. Hybrid Symbiosis Organisms Search Algorithm. In 2016, Nama et al. [32] proposed the hybrid symbiosis organisms search algorithm by embedding the SQI to the original SOS for improving the entire search capability of the algorithm. The SQI is used to get a set of new organisms. It is executed after the completion of the parasitism phase at the present iteration. The formulation of the SQI can be described as follows [32].

Considering two organism $X_{j}$ and $X_{k}(j \neq k)$ where $X_{j}=$ $x_{j, 1}, x_{j, 2}, \ldots, x_{j, D}$ and $X_{k}=x_{k, 1}, x_{k, 2}, \ldots, x_{k, D}$ in the ecosystem, the organism $X_{i}$ is updated by the three-point SQI. The $m$ th dimension of the new organism is calculated by the following equation:

$$
X_{i, m}^{\text {new }}=0.5 \frac{f_{k}\left(\left(X_{i, m}\right)^{2}-\left(X_{j, m}\right)^{2}\right)+f_{i}\left(\left(X_{j, m}\right)^{2}-\left(X_{k, m}\right)^{2}\right)+f_{j}\left(\left(X_{k, m}\right)^{2}-\left(X_{i, m}\right)^{2}\right)}{f_{k}\left(X_{i, m}-X_{j, m}\right)+f_{i}\left(X_{j, m}-X_{k, m}\right)+f_{j}\left(X_{k, m}-X_{i, m}\right)},
$$

where $m=1,2, \ldots, D$ and $f_{i}, f_{j}$, and $f_{k}$ are the fitness values of the $i$ th, $j$ th, and $k$ th organisms, respectively.

The new organism is set to the ecosystem if its fitness value is better than that of the corresponding organism in the ecosystem.

When a new organism is created, it is further checked for boundary violation. If any organism violates the boundary, that organism will be repaired by the following strategy:

$$
X_{i}= \begin{cases}\mathrm{UB}_{i}+\operatorname{rand}(0,1) \times\left(\mathrm{UB}_{i}-\mathrm{LB}_{i}\right), & \text { if } X_{i}<\mathrm{LB}_{i}, \\ \mathrm{UB}_{i}-\operatorname{rand}(0,1) \times\left(\mathrm{UB}_{i}-\mathrm{LB}_{i}\right), & \text { if } X_{i}>\mathrm{UB}_{i},\end{cases}
$$

where $\mathrm{LB}_{i}$ and $\mathrm{UB}_{i}$ are the lower and upper bounds of the $i$ th organism, respectively.

The pseudocode of the SQI-SOS algorithm is depicted in Algorithm 1.

\section{Implementation of SQI-SOS to OCP Problem}

4.1. Initialization. A population of organisms is created by a matrix with Eco_size rows and $D$ columns. Each row represents a solution vector with $4 n$ elements ( $n$ is the number of capacitors). The first $n$ elements are buses chosen for capacitors installation. Each element of this part is a natural number. The remaining elements are the sizes of capacitors 
Set control parameters (dimension of problem D, ecosystem size Eco_size, and maximum number of iteration itermax) Initialize the population of organisms randomly

Set $i$ ter $=1$

while (iter < itermax)

Identify the best organism $X_{\text {best }}$ in an ecosystem;

for $i=1$ : Eco_size

\% Mutualism Phase \%

Randomly select one organism $X_{j}$, where $X_{j} \neq X_{i}$;

Modify organisms $X_{i}$ and $X_{j}$ using equations (10)-(12);

Check the new organisms for boundary violation and repair according to equation (15);

Calculate fitness value of the new organisms;

Update the new organisms with better fitness;

\% Commensalism Phase \%

Randomly select one organism $X_{j}$, where $X_{j} \neq X_{i}$;

Modify organism $X_{i}$ with the help of organism $X_{j}$ using equation (13);

Check the new organism for boundary violation and repair according to equation (15);

Calculate fitness value of the new organism;

Update the new organism with better fitness;

\% Parasitism Phase \%

Randomly select one organism $X_{j}$, where $X_{j} \neq X_{i}$;

Modify organism $X_{i}$ according to Section 3.1.3;

Check the new organism for boundary violation and repair according to equation (15);

Calculate fitness value of the new organism;

Update the new organism with better fitness;

end

for $i=1$ : Eco_size

Randomly select two organisms $X_{j}$ and $X_{k}$, where $X_{j} \neq X_{k} \neq X_{i}$;

Modify organism $X_{i}$ according to equation (14);

Check the new organism for boundary violation and repair according to equation (15);

Calculate the fitness value of the new organism;

Update the new organism with better fitness;

end

iter $=$ iter +1 ;

end

Algorithm 1: Pseudocode of the SQI-SOS algorithm.

at the corresponding load levels. Thus, the solution vector for the OCP problem is formed as follows:

$$
X_{d}=[\underbrace{x_{1}, \ldots, x_{n}}_{\text {locations }} \underbrace{Q_{C, 11}, \ldots, Q_{C, 1 n}}_{\text {kVArs in load level 1 }} \underbrace{Q_{C, 21}, \ldots, Q_{C, 2 n}}_{\text {kVArs in load level 2 }} \underbrace{Q_{C, 31}, \ldots, Q_{C, 3 n}}_{\text {kVArsin load level 3 }}] ; \quad d=1, \ldots, \text { Eco_size. }
$$

In the SQI-SOS, each organism of the population is randomly initialized. The solution for the number of buses and sizes of capacitors for each load level is initialized as follows:

$$
\begin{gathered}
x_{i}=\operatorname{round}\left[x_{\min , i}+\operatorname{rand}_{1} \times\left(x_{\max , i}-x_{\min , i}\right)\right] ; \quad i=1, \ldots, n, \\
Q_{C, i j}=Q_{C \min , i j}+\operatorname{rand}_{1} \times\left(Q_{C \max , i j}-Q_{C \min , i j}\right) ; \quad i=1, \ldots, n ; j=1, \ldots, L .
\end{gathered}
$$

For the size of capacitors, there are two different ways to initialize before starting the optimization process depending on the study cases. In the case with continuous capacitor size, the capacitor sizes corresponding to each load level are initialized using equation (20). Meanwhile, for the actual discrete capacitor size, a novel initialization process is proposed as follows.

Assuming that the actual capacitor size has a range of $\left[0 \cdots Q_{C \max }\right]$ with the increment step of $\Delta Q_{C}$. As a result, there will be $N_{\max }=\left(\left(Q_{C \max } / \Delta Q_{C}\right)+1\right)$ discrete values of capacitor size in the search space. Firstly, these discrete size values are sorted in the ascending order, and then they will be numbered from Ind $\mathrm{Cmin}_{\text {min }}$ to Ind $\mathrm{C}_{\mathrm{max}}$ corresponding to the values from 1 to $N_{\max }$. Obviously, each discrete size value will be identified by an index $\operatorname{Ind}_{C}$. Also, a randomization in 
the initial discrete size initialization process can be fulfilled thanks to the manipulation of equation (21). Thus, capacitor size with the actual discrete value can be obtained by using equation (22). This procedure can be demonstrated as follows:

$$
\begin{aligned}
Q_{C} & =\left[0 \cdots Q_{C \max }\right], \\
\operatorname{Ind}_{C} & =\left[\operatorname{Ind}_{C \min } \cdots \operatorname{Ind}_{C \max }\right]=\left[1 \cdots N_{\max }\right], \\
\operatorname{Ind}_{C, i j} & =\operatorname{round}\left[\operatorname{Ind}_{C \min , i j}+\operatorname{rand}_{1} \times\left(\operatorname{Ind}_{C \max , i j}-\operatorname{Ind}_{C \min , i j}\right)\right] ; \quad i=1, \ldots, n ; j=1, \ldots, L, \\
Q_{C, i j} & =Q_{C}\left(\operatorname{Ind}_{C, i j}\right),
\end{aligned}
$$

where $\operatorname{rand}_{1}$ is a uniformly distributed random number in $[0,1]$ for each population of organisms; $\operatorname{Ind}_{C, i j}$ is an index representing the $i$ th capacitor's capacity with a discrete value in the $j$ th load level; $\operatorname{Ind}_{C \min , i j}$ and $\operatorname{Ind}_{C \max , i j}$ are the lower and upper limits of the index that deputize the discrete size value of the $i$ th capacitor in the $j$ th load level, respectively.
After initialization, each organism needs to be evaluated by calculating its fitness function. The fitness function is formulated based on two components of the objective function and dependent variables. These dependent variables are the inclusion of bus voltages, line flows, power factor, and maximum allowable reactive power. The fitness function is calculated as follows:

$$
F_{T}=\operatorname{Cost}+K_{v} \sum_{i=1}^{N_{b}}\left(V_{i}-V_{i}^{\mathrm{lim}}\right)^{2}+K_{f} \sum_{k=1}^{n_{b r}}\left(\mathrm{PF}_{k}-\mathrm{PF}_{k}^{\mathrm{lim}}\right)^{2}+K_{p}\left(\mathrm{PF}_{\text {overall }}-\mathrm{PF}^{\mathrm{lim}}\right)^{2}+K_{q}\left(\mathrm{Q}_{\mathrm{TC}}-\mathrm{Q}_{\mathrm{TC}}^{\lim }\right)^{2}
$$

where Cost is the objective function in equation (1) and $K_{v}$, $K_{f}, K_{p}$, and $K_{q}$ are the penalty factors for bus voltages, line flows, power factor, and maximum allowable reactive power, respectively. In this study, the used penalty factors are set to 100000 .

The limit values of the dependent variables in equation (23) are expressed as the following equation:

$$
x^{\lim }= \begin{cases}x_{\max }, & \text { if } x<x_{\min } \\ x_{\min }, & \text { if } x<x_{\max } \\ x, & \text { otherwise }\end{cases}
$$

where $x$ represents the calculated value of $V_{i}, \mathrm{PF}_{k}, \mathrm{PF}_{\text {overall, }}$, and $Q_{\mathrm{TC}}$ and $x^{\lim }$ represents the limits of $V_{i}, \mathrm{PF}_{k}, \mathrm{PF}$, and $Q_{\text {TC. }}$

4.2. Stopping Criteria. This study uses the maximum number of iterations (itermax) as the stopping condition. The optimization process of the algorithm is stopped when the number of iterations (iter) is equal to the maximum number of iterations (itermax).

4.3. Overall Procedure. The flowchart of the proposed SQISOS method for solving the OCP problem is given in Figure 1.

\section{Numerical Results}

To validate the effectiveness of the proposed SQI-SOS algorithm, it is tested on several test systems including 33-bus, 69-bus, and 119-bus radial distribution networks to find the optimal locations and sizes of capacitors for minimizing the objective function as formulated in Section 2. In addition, two scenarios including Scenario 1: constant power (CP) load model with different load levels and Scenario 2: voltagedependent load model with maximum load demand have been adopted for investigations. Moreover, in Scenario 1 of this study, the proposed SQI-SOS is adapted to deal with both continuous and discrete sizing variables of the OCP problem. More specifically, in the case of the continuous size variable, the results are theoretically significant while the results in the case of the discrete size variable suit for practical applications. Note that the solution methods are applied to solve the problem with the continuous capacitor size variable named as $\mathrm{SOS}_{\mathrm{c}}$ and SQI-SOS .

The implementation of the SQI-SOS to the OCP problem is coded in the Matlab R2016a platform, and 50 independent trials are run on a computer with Intel core i5-3337U CPU of $1.80 \mathrm{GHz}$ speed and $8 \mathrm{~GB}$ RAM. The Matpower 6.0 toolbox [35] is used for power flow calculation.

5.1. Assumptions, Control Parameters, and Constraints. In order to examine variable load conditions in Scenario 1, it is assumed that the networks are operated at three load levels: 0.5 (light), 0.75 (medium), and 1.0 (full) for time percentages 


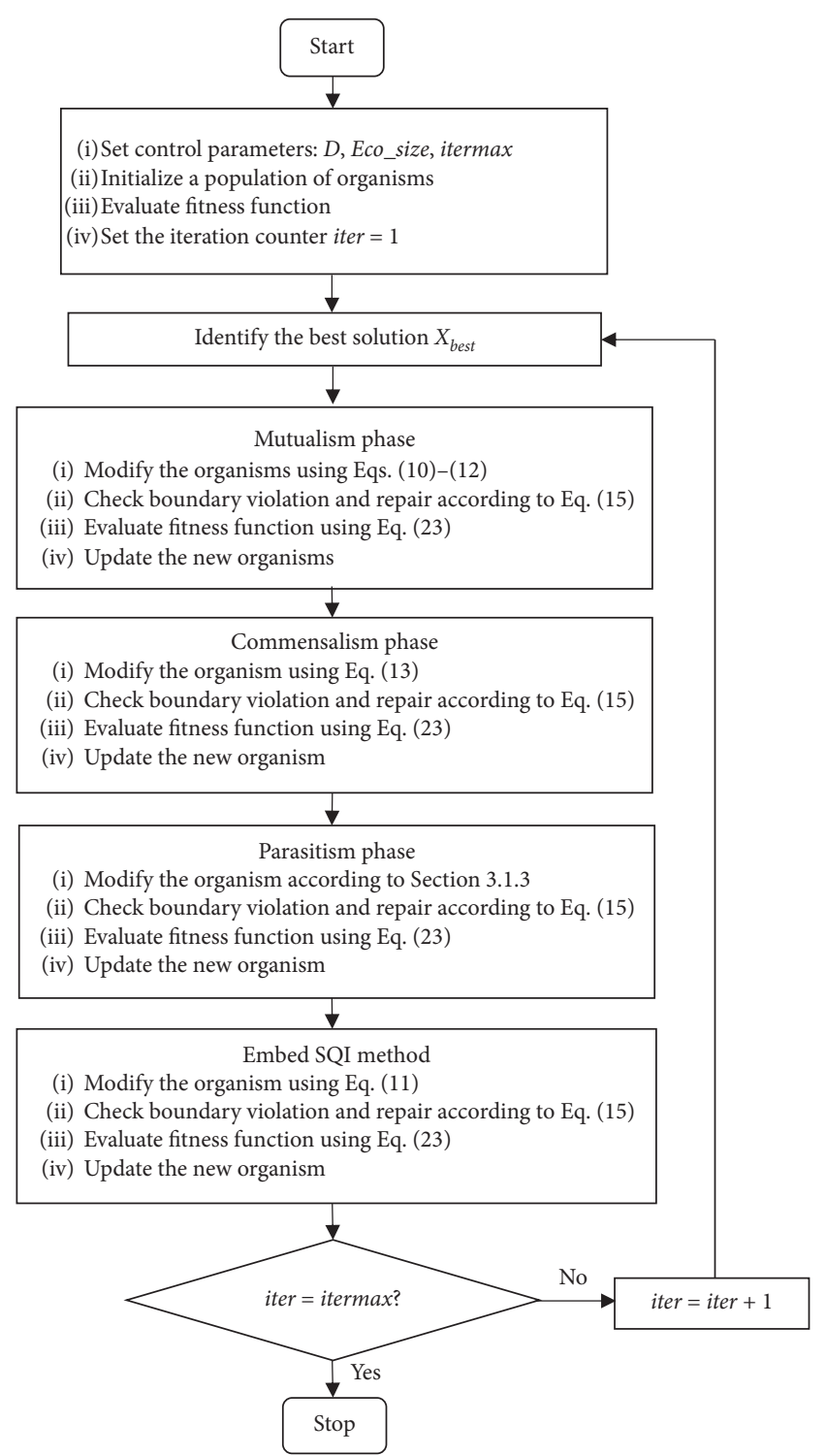

FIGURE 1: Flowchart of the SQI-SOS for solving the OCP problem.

of 25,35 , and $40 \%$, respectively. To calculate the total cost, the rates stated in Table 2 are applied. In addition, the net yearly savings are calculated as follows:

$$
\mathrm{NYS}=A-C,
$$

where NYS is termed as the net yearly savings; $A$ is the yearly energy cost savings; $C$ is the cost of capacitors calculated by the sum of capacitor purchase, operation, and installation costs.

There are two control parameters of the SQI-SOS (i.e., ecosystem size Eco_size and maximum number of iteration itermax) that have to be predetermined. The ecosystem size and the maximum number of iterations can be fixed depending on the complexity and dimension of optimization problems. They can be set to a small value for a smallscale problem and to a higher value for a large-scale problem. The parameter setting for the SQI-SOS algorithm for all test systems is given in Table 3. Table 3 also provides
TABLE 2: Rates for energy, purchase, operation, and maintenance costs.

\begin{tabular}{lc}
\hline Item & Rate \\
\hline Average energy cost $(\mathrm{KP})$ & $0.06 \mathrm{k} \$ / \mathrm{kWh}$ \\
Purchase cost $(\mathrm{KC})$ & $3 \mathrm{k} \$ / \mathrm{kVAr}$ \\
Installation cost $(\mathrm{Kci})$ & $10001 \$ /$ location \\
Operating cost $(\mathrm{Kco})$ & $300 \mathrm{y} \$ /$ year $/$ location \\
Hours per year $(\mathrm{T})$ & 8760.0000 \\
\hline
\end{tabular}

the information for the setting of inequality constraints for the OCP problem. Regarding the inequality constraint setting, the maximum limit of power flow is proposed to control the power flow in each line after reactive power compensation. The upper limit of the overall power factor is set to 1 for all test systems, whereas its lower limit is set to 0.95 for the 33-bus system based on the repeated trials and 0.9 for both the 69-bus and 119-bus systems according to the previous studies [16-18]. The upper and lower limits of system voltage ( 0.9 and 1.05 , respectively) are applied to all the tested systems. In addition, for the test distribution systems, the numbers of capacitors to be installed are different. The reason is that these numbers of capacitors are chosen based on the basis of the effect assessment of the different numbers of capacitors on the system performance, i.e., the improvement in the total annual cost with compensation. The experimented results reveal that the penetration of the chosen number of capacitors into each system leads to a significant reduction in the total cost as compared to that of the remaining numbers of capacitors, but this penetration still fulfills in all relevant operational constraints.

5.2. 33-Bus Test System. The first test system is a 33-bus radial distribution network with the line and load data from [36]. This system supplies a total power load demand of 3.72 MW and 2.3 MVAr at a voltage level of $12.66 \mathrm{kV}$.

5.2.1. Scenario 1: CP Load Model with Different Load Levels. In the first scenario, the OCP problem was examined with a CP load model to make a performance comparison with previously reported methods.

Table 4 shows the optimal siting and sizing of capacitors obtained by the tested SQI-SOS ${ }_{\mathrm{c}}$ and $\mathrm{SOS}_{\mathrm{c}}$ as well as the proposed SQI-SOS and SOS at different load levels. Fixed and switched capacitors on the load levels by the proposed SQI-SOS and SOS are provided in Table 4 as well. As seen from Table 4, for the case of full load level, the SQI-SOS provides the optimal locations to install capacitors which are buses 14, 25, and 30 with the optimal capacitor sizes of $300 \mathrm{kVAr}, 200 \mathrm{kVAr}$, and $900 \mathrm{kVAr}$, respectively.

Table 5 shows the system conditions before and after the installation of capacitors at different load levels. For the case of $100 \%$ load level, before the installation of capacitors, the system has a real power loss of $210.9875 \mathrm{~kW}$, minimum voltage of 0.9038 p.u., overall power factor of 0.8490 lagging, and total annual cost of 71,737.7 \$. After the capacitors are installed according to the proposed SQI-SOS method, the 
TABLE 3: Parameter setting for the SQI-SOS algorithm and inequality constraint setting.

\begin{tabular}{|c|c|c|c|}
\hline Item & 33-bus test system & 69-bus test system & 119-bus test system \\
\hline Population size & 90 & 90 & 150 \\
\hline Maximum number of iterations & 100 & 100 & 200 \\
\hline Maximum power flow-MPF $(\mathrm{kW})$ & $3925.99\left(\# L_{1-2}\right)$ & $4027.1\left(\# L_{1-2}\right)$ & $10677.9\left(\# L_{1-2}\right)$ \\
\hline Maximum limit of power flow-MLPF $(\mathrm{kW})$ & 4000 & 4200 & 11000 \\
\hline Bus voltage constraint & & $0.9 \leq\left|V_{i}\right| \leq 1.05$ & \\
\hline Power factor constraint & $0.95 \leq \mathrm{PF}_{\text {overall }} \leq 1$ & $0.9 \leq \mathrm{PF}_{\text {overall }} \leq 1$ & $0.9 \leq \mathrm{PF}_{\text {overall }} \leq 1$ \\
\hline Number of capacitors to be installed & 3 & 2 & 8 \\
\hline Allowable capacitor range & 0-1500 kVAr for & $\begin{array}{l}\text { size variables; } 0-1 \\
\mathrm{Ar} \text { for discrete size }\end{array}$ & with the fixed step of \\
\hline
\end{tabular}

TABLE 4: Optimal siting and sizing of capacitors for the 33-bus system with the CP load model at different load levels.

\begin{tabular}{|c|c|c|c|c|}
\hline Load level & Method & Optimal siting and sizing in $\mathrm{kVAr}$ & Total kVAr & Total kVAr demand \\
\hline Light $50 \%$ & $\begin{array}{l}\text { SOSc } \\
\text { SQI-SOSc } \\
\text { SOS } \\
\text { SQI-SOS }\end{array}$ & $\begin{array}{l}(13,191.51) ;(25,200.72) ;(30,516.28) \\
(13,191.48) ;(25,200.85) ;(30,516.33) \\
\quad(14,200) ;(25,200) ;(30,500) \\
\quad(14,200) ;(25,200) ;(30,500)\end{array}$ & $\begin{array}{c}908.51 \\
908.67 \\
900 \\
900 \\
\end{array}$ & 1150 \\
\hline Medium 75\% & $\begin{array}{l}\text { SOSc } \\
\text { SQI-SOSc } \\
\text { SOS } \\
\text { SQI-SOS }\end{array}$ & $\begin{array}{c}(13,295.44) ;(25,200.72) ;(30,789.82) \\
(13,295.42) ;(25,200.85) ;(30,789.84) \\
\quad(14,300) ;(25,200) ;(30,800) \\
(14,300) ;(25,200) ;(30,800)\end{array}$ & $\begin{array}{c}1285.99 \\
1286.11 \\
1300 \\
1300 \\
\end{array}$ & 1725 \\
\hline Full $100 \%$ & $\begin{array}{l}\text { SOSc } \\
\text { SQI-SOSc } \\
\text { SOS } \\
\text { SQI-SOS }\end{array}$ & $\begin{array}{l}(13,325.37) ;(25,200.72) ;(30,900.73) \\
(13,325.37) ;(25,200.85) ;(30,900.75) \\
\quad(14,300) ;(25,200) ;(30,900) \\
\quad(14,300) ;(25,200) ;(30,900)\end{array}$ & $\begin{array}{c}1426.84 \\
1426.97 \\
1400 \\
1400\end{array}$ & 2300 \\
\hline $\begin{array}{l}\text { Final optimal ratings (location and size) } \\
\text { by proposed approach }\end{array}$ & SQI-SOS & \multicolumn{3}{|c|}{$\begin{array}{l}\text { Fixed: }(14,200) ;(25,200) ;(30,500) \\
\text { Switched: }(14,100) ;(30,400) \\
\text { Fixed: }(14,200) ;(25,200) ;(30,500) \\
\text { Switched: }(14,100) ;(30,400)\end{array}$} \\
\hline
\end{tabular}

power loss is reduced from $210.9875 \mathrm{~kW}$ to $141.5439 \mathrm{~kW}$, the minimum voltage is improved from 0.9038 p.u. to 0.9275 p.u., the system overall power factor is corrected from 0.849 lagging to 0.9682 lagging, and the total annual cost is reduced from $71,737.7$ to $56,198.33$ \$. Obviously, with the objective of system operating cost achieved, it leads to an annual net savings of 15,539.36 \$. Although the proposed SQI-SOS and SOS methods provide the same total annual cost, the proposed SQI-SOS obtains the results with a smaller number of iterations than the SOS. It clearly shows that the convergence speed of the proposed SQI-SOS is faster than the original SOS, and this is confirmed as can be seen from Figure 2. Note that this system was first experimented when considering the OCP problem, so a comparison study for calculation performance with the previous approaches cannot be made. In addition, the statistical performance of the proposed SQI-SOS including the worst, best, mean, and standard deviation of the total annual cost is tabulated in Table 5. As shown in Table 5, the standard deviation of solutions yielded by the SQI-SOS is lower than that obtained by the SOS algorithm. This proves that the SQI-SOS method is more robust than the SOS algorithm when applied to this test system. It is worth mentioning here that the simulated actual capacitor sizing results are similar to the simulated theoretical ones, showing the reliability of computation.
Moreover, in $100 \%$ load level, the connection of capacitors into the system results in a remarkable improvement in the bus voltage profile, as shown in Figure 3. In addition, the comparison of lines power flow before and after compensation with the CP load model can be observed in Figure 4. Clearly, the maximum power flow (MPF) on lines 1-2 ( $\left.\# L_{1-2}\right)$ is decreased from $3925.99 \mathrm{~kW}$ to $3856.54 \mathrm{~kW}$ due to optimal compensation by the proposed SQI-SOS, and this value is much lower than the maximum limit of power flow (MLPF) of $4000 \mathrm{~kW}$. Furthermore, the connection of capacitors to the system leads to the reduction of power flow in most lines. The detail of power loss comparison before and after compensation for this system corresponding to the full load level using the SQI-SOS method in each line is given in Table 6. In general, the proposed SQI-SOS method is more suitable than the original SOS algorithm for dealing with the OCP problem in the CP load model of the 33-bus system. The reason is that the exploration ability of the SQI-SOS method is significantly better than that of the original SOS algorithm. Furthermore, the robustness of SQI-SOS is validated compared with the SOS algorithm.

5.2.2. Scenario 2: Voltage-Dependent Load Model with Maximum Load Demand. The test results of the 33-bus system acquired by the applied SOS and proposed SQI-SOS 


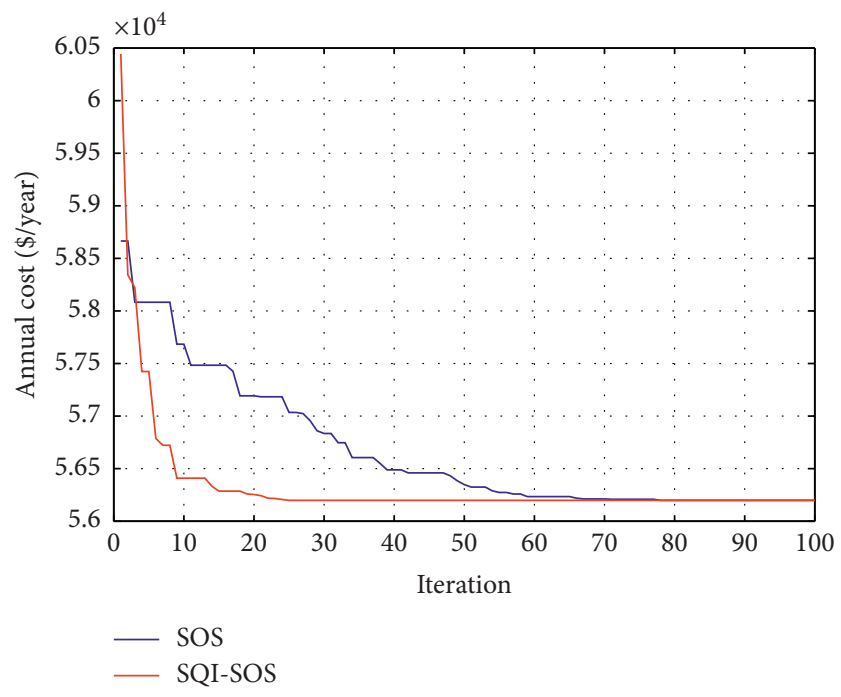

Figure 2: Convergence curves of the total cost of the 33-bus system under the CP load model with $100 \%$ loading.

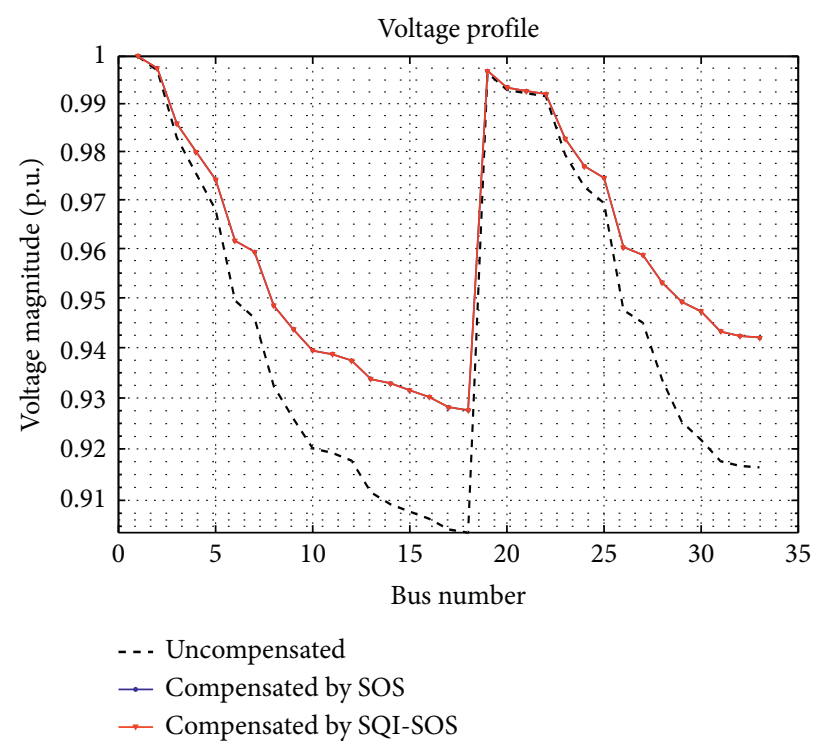

Figure 3: Voltage profile of the 33-bus system before and after compensation with the CP load model at $100 \%$ loading.

methods with different voltage-dependent load models are represented in Table 7. It can be seen that in all the experimented load models, the system performance parameters have been significantly improved with capacitor installation. Table 8 reveals the detailed information on the optimal placements and reactive powers of capacitors for each load model. The reduction in the total annual cost of the system after compensated by the SOS and SQI-SOS can be observed in all the load types as depicted in Figure 5. In the actual mixed load case, the power loss before compensation is $164.9165 \mathrm{~kW}$, and this loss is enhanced after optimal compensation to be $130.0845 \mathrm{~kW}$. The minimum system voltage without compensation is 0.9159 p.u. and is increased to 0.9307 p.u. due to capacitor allocations. Also, the system overall power factor has been appreciably enhanced from 0.8908 lagging to 0.9776 lagging. With the installation of capacitors at the optimal locations and sizes in $\operatorname{kVAr}$ of $\{(13,300) ;(25,250) ;(30,950)\}$, the total system annual cost is reduced to $76772.43 \$$ /year, i.e., the net saving is 9907.66 \$year, compared to 86680.09 \$/year in the uncompensated case. Although the objective values of total costs found are the same, the SOS-SQI requires less number of iterations than the SOS in the searching process as shown in Figure 6. Moreover, the enhancements in the voltage magnitudes in all buses can be perceived as seen in Figure 7. In addition, Figure 8 illustrates the comparison of lines power flow before and after compensation. It is worthy to mention that through the SQI-SOS, the MPF on $\mathrm{L}_{1-2}$ is reduced to $3753.63 \mathrm{~kW}$, which is lower than a maximum limit of power flow (MLPF) of $4000 \mathrm{~kW}$. Moreover, the power flow in most lines for the compensated case is lower than that for 


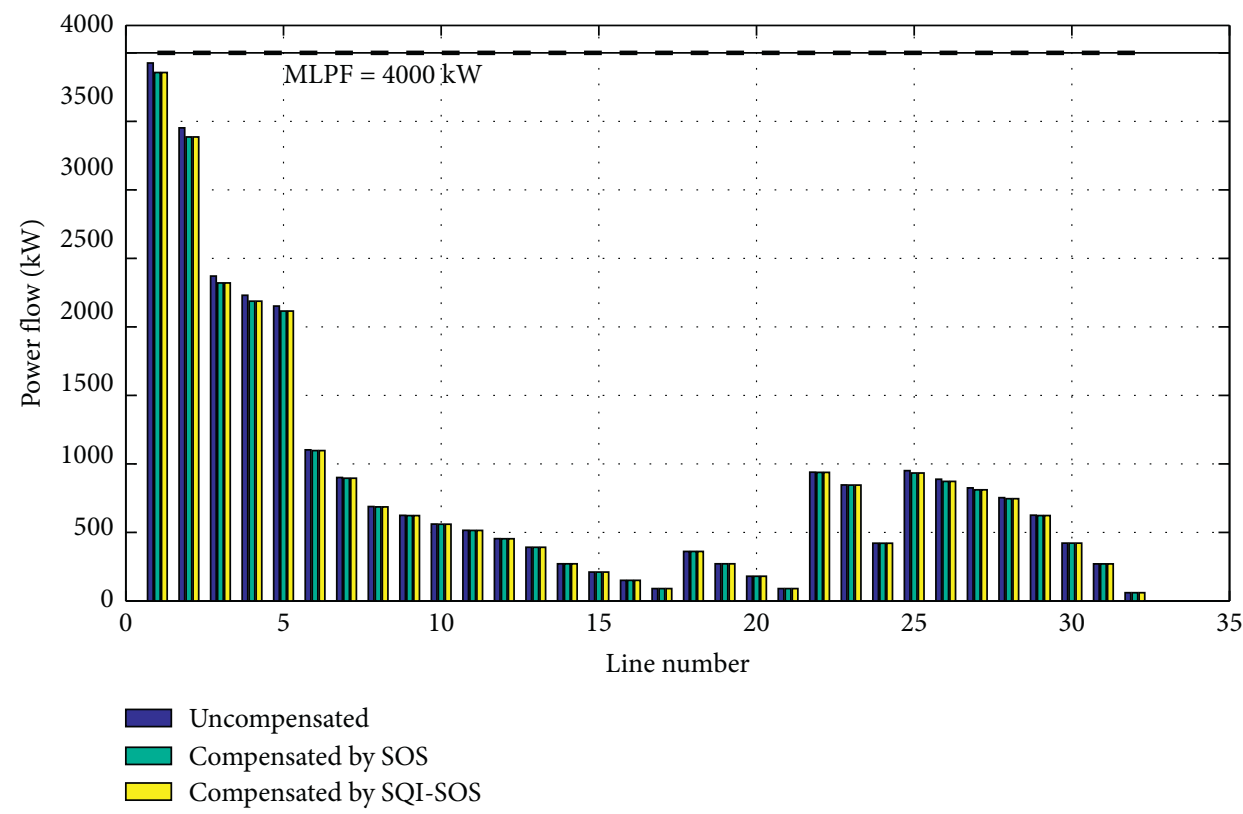

Figure 4: Comparison of lines power flow of the 33-bus system before and after compensation with the CP load model at $100 \%$ loading.

TABLE 5: Comparison results of the 33-bus system before and after compensation with the CP load model at different load levels.

\begin{tabular}{|c|c|c|c|c|c|c|}
\hline \multirow{2}{*}{ Load level } & \multirow{2}{*}{ Item } & \multirow{2}{*}{ Uncompensated } & \multicolumn{4}{|c|}{ Compensated } \\
\hline & & & $\mathrm{SOS}_{\mathrm{c}}$ & SQI-SOS $_{\mathrm{c}}$ & SOS & SQI-SOS \\
\hline \multirow{5}{*}{ Light $50 \%$} & $V_{\min }$, p.u. & 0.9540 & 0.9667 & 0.9667 & 0.9678 & 0.9678 \\
\hline & $\mathrm{P}_{\text {loss }}, \mathrm{kW}$ & 48.7870 & 32.8848 & 32.8848 & 32.916 & 32.916 \\
\hline & $\mathrm{PF}_{\text {overall }}$ & 0.8497 & 0.9904 & 0.9904 & 0.9897 & 0.9897 \\
\hline & MPF kW & 1906.28 & 1890.38 & 1890.38 & 1890.41 & 1890.41 \\
\hline & NVIT $T, K V$ & $\left(\# L_{1-2}\right)$ & $\left(\# L_{1-2}\right)$ & $\left(\# L_{1-2}\right)$ & $\left(\# L_{1-2}\right)$ & $\left(\# L_{1-2}\right)$ \\
\hline \multirow{5}{*}{ Medium 75\% } & $V_{\text {min }}$, p.u. & 0.9295 & 0.9495 & 0.9495 & 0.9512 & 0.9512 \\
\hline & $\mathrm{P}_{\text {loss }}, \mathrm{kW}$ & 113.9869 & 76.1249 & 76.1243 & 76.1849 & 76.1849 \\
\hline & $\mathrm{PF}_{\text {overall }}$ & 0.8494 & 0.9856 & 0.9856 & 0.9864 & 0.9864 \\
\hline & & 2900.23 & 2862.37 & 2862.37 & 2862.43 & 2862.43 \\
\hline & MPF, kW & $\left(\# L_{1-2}\right)$ & $\left(\# L_{1-2}\right)$ & $\left(\# L_{1-2}\right)$ & $\left(\# L_{1-2}\right)$ & $\left(\# L_{1-2}\right)$ \\
\hline \multirow{5}{*}{ Full 100\% } & $V_{\min }$, p.u. & 0.9038 & 0.9271 & 0.9271 & 0.9275 & 0.9275 \\
\hline & $\mathrm{P}_{\text {loss }}, \mathrm{kW}$ & 210.9875 & 141.1855 & 141.1840 & 141.5439 & 141.5439 \\
\hline & $\mathrm{PF}_{\text {overall }}$ & 0.8490 & 0.9698 & 0.9698 & 0.9682 & 0.9682 \\
\hline & & 3925.99 & 3856.18 & 3856.18 & 3856.54 & 3856.54 \\
\hline & $\mathrm{MPF}, \mathrm{kW}$ & $\left(\# L_{1-2}\right)$ & $\left(\# L_{1-2}\right)$ & $\left(\# L_{1-2}\right)$ & $\left(\# L_{1-2}\right)$ & $\left(\# L_{1-2}\right)$ \\
\hline \multicolumn{2}{|c|}{ Total annual cost (\$/year) } & $71,737.7$ & $56,188.36$ & $56,188.36$ & $56,198.33$ & $56,198.33$ \\
\hline \multicolumn{2}{|c|}{ Annual net savings (\$/year) } & - & $15,549.33$ & $15,549.33$ & $15,539.36$ & $15,539.36$ \\
\hline \multicolumn{2}{|c|}{ Worst cost (\$/year) } & - & $56,449.50$ & $56,449.50$ & $56,507.02$ & $56,458.73$ \\
\hline \multicolumn{2}{|c|}{ Best cost (\$/year) } & - & $56,188.36$ & $56,188.36$ & $56,198.33$ & $56,198.33$ \\
\hline \multicolumn{2}{|c|}{ Mean cost (\$/year) } & - & $56,252.59$ & $56,228.78$ & $56,265.06$ & $56,227.01$ \\
\hline \multicolumn{2}{|c|}{ Standard deviation $(\sigma)$} & - & 97.37 & 78.96 & 107.41 & 62.58 \\
\hline
\end{tabular}

the uncompensated case. Based on the experiment results, it can be concluded that the proposed SQI-SOS is capable of dealing with the practical voltage-dependent load model scenarios for this system.

5.3. 69-Bus Test System. The second test system is a 69-bus radial distribution network with the total load demand of 3.8 MW and 2.69 MVAr. The data for branch and load of this system are taken from [37] with a base voltage of $12.66 \mathrm{kV}$.
5.3.1. Scenario 1: CP Load Model with Different Load Levels. In this scenario, the siting and sizing of capacitors obtained by the proposed SQI-SOS, applied SOS, and other methods are shown in Table 9 with different load levels. Table 9 also provides fixed and switched capacitors on the load levels. At the full level of loads, the SQI-SOS provides the optimal locations which are buses 18 and 61 corresponding to optimal capacitor sizes of $250 \mathrm{kVAr}$ and $1100 \mathrm{kVAr}$ to install the capacitors. The detail of power loss comparison before 
TABLE 6: Results of real power loss in all lines of the 33-bus system before and after the installation of capacitors.

\begin{tabular}{|c|c|c|}
\hline \multirow{2}{*}{ Line } & \multicolumn{2}{|c|}{ Real power loss $(\mathrm{kW})$} \\
\hline & Uncompensated & Compensated by SQI-SOS \\
\hline $1-2$ & 12.300 & 9.127 \\
\hline $2-3$ & 52.077 & 37.285 \\
\hline $3-4$ & 20.053 & 13.143 \\
\hline $4-5$ & 18.850 & 12.187 \\
\hline $5-6$ & 38.566 & 24.693 \\
\hline $6-7$ & 1.946 & 1.588 \\
\hline $7-8$ & 11.873 & 9.488 \\
\hline $8-9$ & 4.266 & 3.366 \\
\hline $9-10$ & 3.620 & 2.826 \\
\hline $10-11$ & 0.565 & 0.437 \\
\hline $11-12$ & 0.899 & 0.710 \\
\hline $12-13$ & 2.721 & 2.234 \\
\hline $13-14$ & 0.744 & 0.658 \\
\hline $14-15$ & 0.364 & 0.346 \\
\hline $15-16$ & 0.287 & 0.273 \\
\hline $16-17$ & 0.257 & 0.244 \\
\hline $17-18$ & 0.054 & 0.051 \\
\hline $2-19$ & 0.161 & 0.161 \\
\hline $19-20$ & 0.832 & 0.831 \\
\hline $20-21$ & 0.101 & 0.101 \\
\hline $21-22$ & 0.044 & 0.044 \\
\hline $3-23$ & 3.182 & 2.740 \\
\hline $23-24$ & 5.144 & 4.389 \\
\hline $24-25$ & 1.288 & 1.038 \\
\hline $6-26$ & 2.602 & 1.199 \\
\hline $26-27$ & 3.330 & 1.466 \\
\hline $27-28$ & 11.306 & 4.728 \\
\hline $28-29$ & 7.837 & 3.077 \\
\hline $29-30$ & 3.897 & 1.392 \\
\hline $30-31$ & 1.594 & 1.509 \\
\hline $31-32$ & 0.213 & 0.202 \\
\hline $32-33$ & 0.013 & 0.012 \\
\hline
\end{tabular}

and after compensation for this system corresponding to the full load level using the SQI-SOS method in each line is given in Table 10.

To verify the efficacy of the proposed SQI-SOS, the resulting solutions acquired by the SQI-SOS are compared with those from the other well-established methods such as SOS, SQI-SOS, SOS $_{c}$, CSA [16], IHA [17], and FPA [18], as shown in Table 11. For the case of $100 \%$ load level, before reactive power compensation, the system has a real power loss of $225.0006 \mathrm{~kW}$ with a minimum voltage of 0.9092 p.u. The overall power factor of the system is 0.8213 lagging. After reactive power compensation by the SQI-SOS method, the real power loss of the system is decreased to $148.4248 \mathrm{~kW}$, the minimum system voltage is enhanced to 0.9281 p.u., and the system overall power factor is corrected to 0.9415 . Regarding the total annual cost, it is reduced from $76,349.9$ \$ to $57,043.14$ \$ by the SQI-SOS for the case of full load level. As observed from Table 11, both the proposed SQI-SOS and original SOS find the same total annual cost. However, the SQI-SOS converges at the optimum result faster than the SOS as manifested in Figure 9. Moreover, the statistical performance parameters such as the worst, best, mean, and standard deviation values of the total annual cost by the SQI-SOS method are better than the ones by the SOS algorithm. Also, the SQI-SOS method yields the lowest total annual cost compared to that from previously reported approaches. Specifically, the best total annual cost attained by the SQI-SOS method is $57,043.14 \$$, whereas the best cost by CSA [16], IHA [17], and FPA [18] is 58,074.59 \$, $58,165.60$ \$, and 57,753.11 \$, respectively. Besides, the results pertaining to the actual capacitor sizing case are also similar to the results from the theoretical capacitor sizing case. This again confirms the reliability of computation. Furthermore, in Figure 10, the improvement of the bus voltage profile of the system in the $100 \%$ load level with the presence of capacitors can be verified. Figure 11 depicts the lines power flow change before and after capacitor allocation. It is realized that MPF on $\mathrm{L}_{1-2}$ is reduced to $3,950.52 \mathrm{~kW}$ by the proposed SQI-SOS, and it is still within permissible limit. In addition, the power flow on most of the lines is diminished due to reactive power compensation. Generally, the proposed SQI-SOS method outperforms the previously published methods regarding the gain of the lowest total annual cost for the test system in this scenario. On the other hand, the SQI-SOS approach introduces a fairly new solution to the OCP problem for the 69-bus system with the CP load model. Therefore, the SQI-SOS method exposes the ability not only to improve the convergence speed, but also to 
TABLE 7: Comparative results of the 33-bus system after compensation with different load models.

\begin{tabular}{|c|c|c|c|c|}
\hline \multirow{2}{*}{ Load type } & \multirow{2}{*}{ Item } & \multirow{2}{*}{ Uncompensated } & \multicolumn{2}{|c|}{ Compensated } \\
\hline & & & SOS & SQI-SOS \\
\hline \multirow{6}{*}{ Industrial load } & $V_{\min }$ (bus) & $0.9152(18)$ & $0.9305(18)$ & $0.9305(18)$ \\
\hline & $\mathrm{P}_{\text {loss }}, \mathrm{kW}$ & 167.7916 & 135.9869 & 135.9869 \\
\hline & $\mathrm{PF}_{\text {overall }}$ & 0.9042 & 0.9809 & 0.9809 \\
\hline & Total cost, \$/year & $88,191.24$ & $80,024.69$ & $80,024.69$ \\
\hline & Annual savings (\$/year) & - & $8,166.55$ & $8,166.55$ \\
\hline & $\mathrm{MPF}, \mathrm{kW}$ & $\begin{array}{c}3,851.37 \\
\left(\# L_{1-2}\right)\end{array}$ & $\begin{array}{c}3,825.86 \\
\left(\# L_{1-2}\right)\end{array}$ & $\begin{array}{c}3,825.86 \\
\left(\# L_{1-2}\right)\end{array}$ \\
\hline \multirow{6}{*}{ Residential load } & $V_{\min }$ (bus) & $0.9160(18)$ & $0.9314(18)$ & $0.9314(18)$ \\
\hline & $\mathrm{P}_{\text {loss }}, \mathrm{kW}$ & 164.5408 & 127.1548 & 127.1548 \\
\hline & $\mathrm{PF}_{\text {overall }}$ & 0.8822 & 0.9766 & 0.9766 \\
\hline & Total cost, \$/year & $86,482.65$ & $75,232.54$ & $75,232.54$ \\
\hline & Annual savings (\$/year) & - & $11,250.10$ & $11,250.10$ \\
\hline & $\mathrm{MPF}, \mathrm{kW}$ & $\begin{array}{c}3,723.14 \\
\left(\# L_{1-2}\right)\end{array}$ & $\begin{array}{c}3,718.49 \\
\left(\# L_{1-2}\right)\end{array}$ & $\begin{array}{c}3,718.49 \\
\left(\# L_{1-2}\right)\end{array}$ \\
\hline \multirow{6}{*}{ Commercial load } & $V_{\text {min }}$ (bus) & $0.9175(18)$ & $0.9236(18)$ & $0.9236(18)$ \\
\hline & $\mathrm{P}_{\text {loss }}, \mathrm{kW}$ & 159.5012 & 127.1272 & 127.1272 \\
\hline & $\mathrm{PF}_{\text {overall }}$ & 0.8707 & 0.9580 & 0.9580 \\
\hline & Total cost, \$/year & $83,833.85$ & $74,168.07$ & $74,168.07$ \\
\hline & Annual savings (\$/year) & - & $9,665.77$ & $9,665.77$ \\
\hline & $\mathrm{MPF}, \mathrm{kW}$ & $\begin{array}{c}3,625.88 \\
\left(\# L_{1-2}\right)\end{array}$ & $\begin{array}{c}3,625.81 \\
\left(\# L_{1-2}\right)\end{array}$ & $\begin{array}{c}3,625.81 \\
\left(\# L_{1-2}\right)\end{array}$ \\
\hline \multirow{6}{*}{ Mixed load } & $V_{\min }$ (bus) & $0.9159(18)$ & $0.9307(18)$ & $0.9307(18)$ \\
\hline & $\mathrm{P}_{\text {loss }}, \mathrm{kW}$ & 164.9165 & 130.0845 & 130.0845 \\
\hline & $\mathrm{PF}_{\text {overall }}$ & 0.8908 & 0.9776 & 0.9776 \\
\hline & Total cost, \$/year & $86,680.09$ & $76,772.43$ & $76,772.43$ \\
\hline & Annual savings (\$/year) & - & $9,907.66$ & $9,907.66$ \\
\hline & $\mathrm{MPF}, \mathrm{kW}$ & $\begin{array}{c}3,765.53 \\
\left(\# L_{1-2}\right)\end{array}$ & $\begin{array}{c}3,753.63 \\
\left(\# L_{1-2}\right)\end{array}$ & $\begin{array}{c}3,753.63 \\
\left(\# L_{1-2}\right)\end{array}$ \\
\hline
\end{tabular}

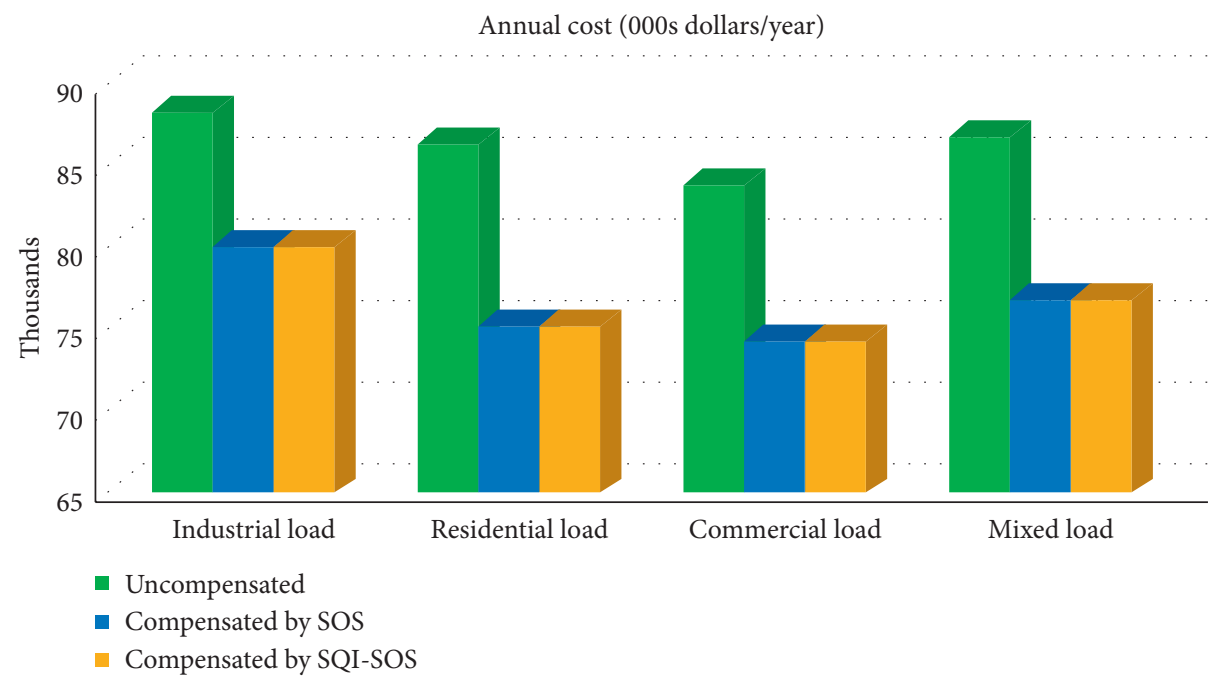

Figure 5: Annual cost of the 33-bus system before and after compensation with different load models.

enhance the robustness of the original SOS algorithm when solving the problem under the CP load model.

5.3.2. Scenario 2: Voltage-Dependent Load Model with Maximum Load Demand. The OCP results for the 69-bus system with voltage-dependent load models are tabulated in Table 12. From Table 12, it is observed that after optimal compensation by the proposed SQI-SOS, the system conditions are remarkably improved in all the studied load models. Also, the optimal locations and sizes of capacitors obtained by the methods for the different load types are given in Table 13. Figure 12 shows the comparison of the total system annual cost with and without capacitor 


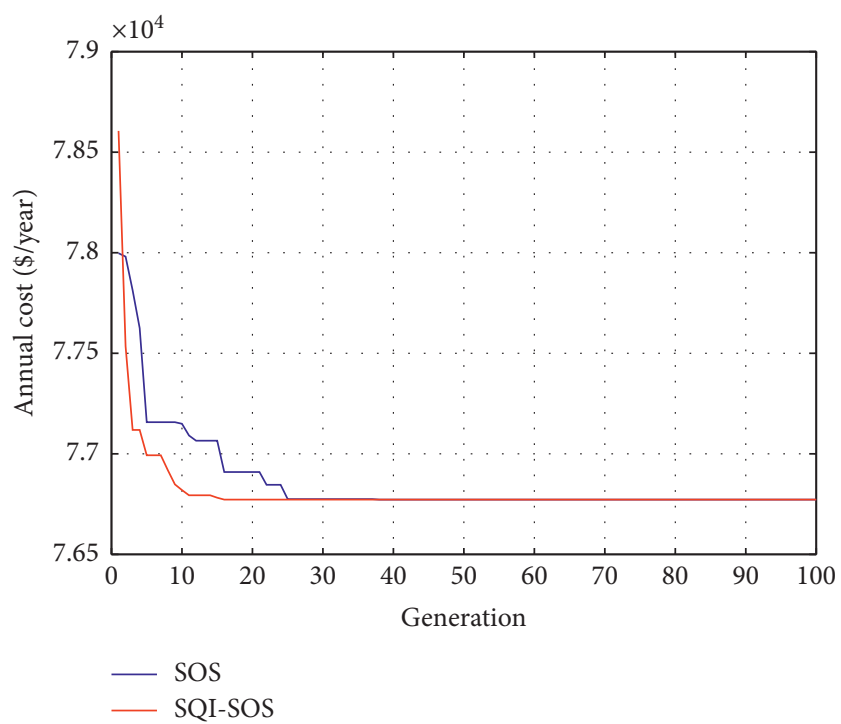

FIGURE 6: Convergence curves of the total cost of the 33-bus system with the mixed load model.

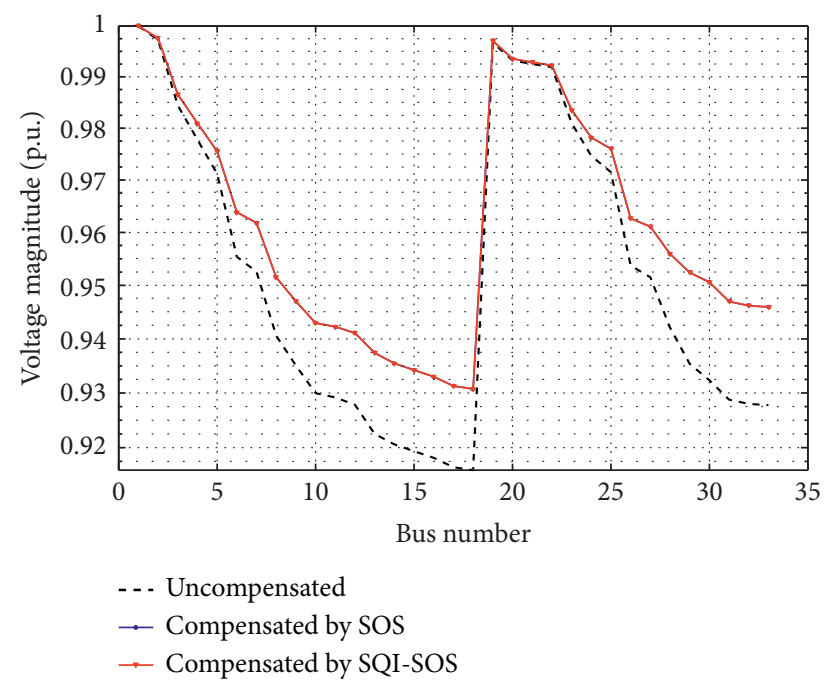

FiguRE 7: Voltage profile of the 33-bus system before and after compensation with the mixed load model.

allocations in different load models. For the practical mix load model, the proposed approach offers a solution with the connection of only two capacitor placements of $\{18,61\}$ with respective sizes in $\mathrm{kVAr}$ of $\{300,1150\}$. As a result, the total system annual cost is reduced to $77,892.02$ \$/year corresponding to a net savings of $12,191.18$ \$/year. In addition, the real power loss is decreased from $171.3912 \mathrm{~kW}$ (uncompensated case) to $134.9734 \mathrm{~kW}$ (compensated case). Furthermore, the minimum voltage and overall power factor of the system are corrected from 0.9199 p.u. to 0.9325 p.u. and from 0.8606 lagging to 0.9512 lagging, respectively. Moreover, Figure 13 shows that the proposed SQI-SOS outperforms the SOS in terms of convergence speed when examining this load model. The improvements in the system voltage profile can be observed in Figure 14. Finally, the power flow in lines before and after compensation can be compared through a clustered column graph as depicted in Figure 15. It can be observed from the figure that the MPF on $\mathrm{L}_{1-2}$ is decreased from $3,863.60 \mathrm{~kW}$ (in the uncompensated case) to $3,844.38 \mathrm{~kW}$ (in the compensated case). Besides, the power flow in most lines is improved after compensation. From the simulated results, it can be realized that the proposed SQI-SOS method can effectively deal with the problem in the voltagedependent load models.

5.4. 119-Bus Test System. The performance of the proposed SQI-SOS is finally tested on a large-scale radial distribution network with 119 buses. The total load demand of this system is $22.709 \mathrm{MW}$ and 17.041 MVAr with a rated voltage of $11 \mathrm{kV}$. The system data are referred from [38]. 


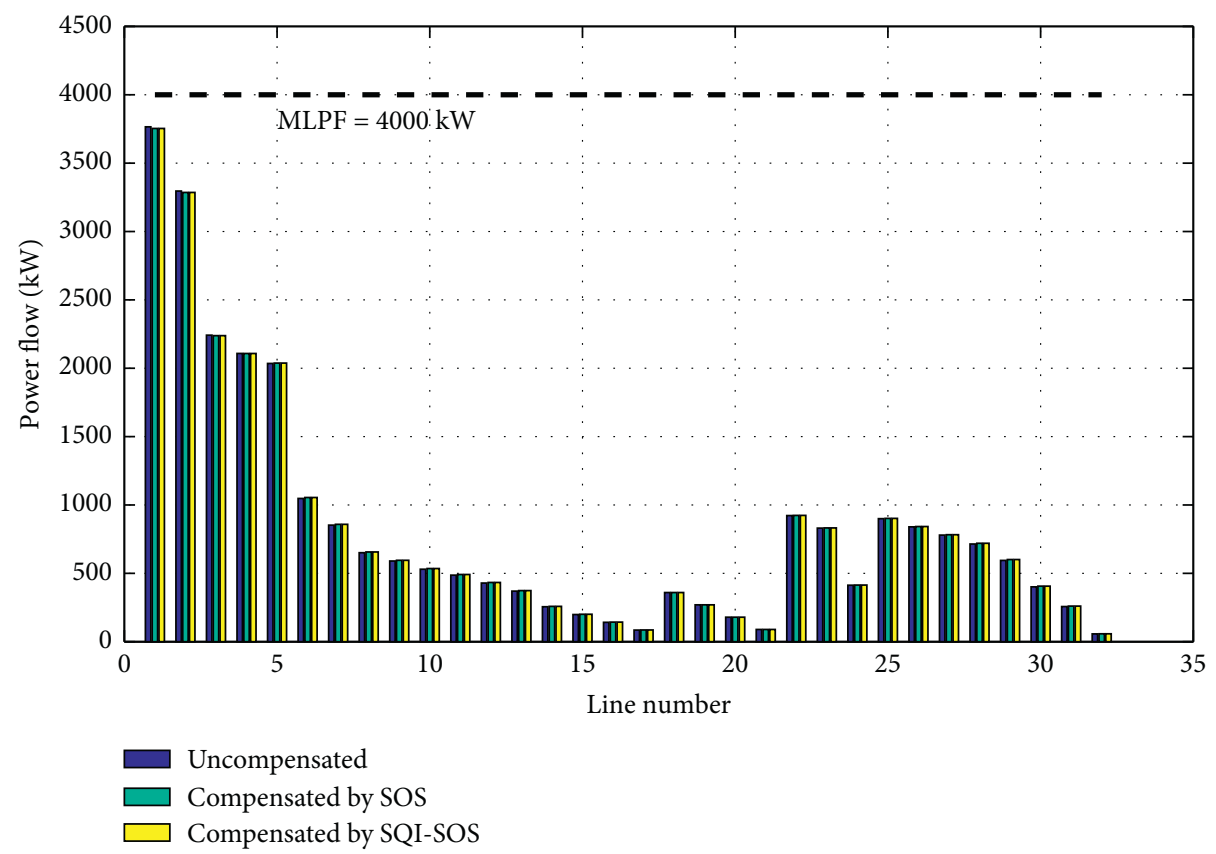

Figure 8: Comparison of lines power flow of the 33-bus system before and after compensation with the mixed load model.

TABLE 8: Optimal locations and kVArs of capacitors for the 33-bus system with different load models.

\begin{tabular}{|c|c|c|c|}
\hline Load type & Location and injected $\mathrm{kVAr}$ & Total kVAr & Method \\
\hline \multirow{2}{*}{ Industrial load } & $(13,350) ;(25,250) ;(30,950)$ & 1550 & SOS \\
\hline & $(13,350) ;(25,250) ;(30,950)$ & 1550 & SQI-SOS \\
\hline \multirow{2}{*}{ Residential load } & $(13,300) ;(25,250) ;(30,950)$ & 1500 & SOS \\
\hline & $(13,300) ;(25,250) ;(30,950)$ & 1500 & SQI-SOS \\
\hline \multirow{2}{*}{ Commercial load } & $(5,350) ;(25,100) ;(30,700)$ & 1150 & SOS \\
\hline & $(5,350) ;(25,100) ;(30,700)$ & 1150 & SQI-SOS \\
\hline \multirow{2}{*}{ Mixed load } & $(13,300) ;(25,250) ;(30,950)$ & 1500 & SOS \\
\hline & $(13,300) ;(25,250) ;(30,950)$ & 1500 & SQI-SOS \\
\hline
\end{tabular}

5.4.1. Scenario 1: CP Load Model with Different Load Levels. Table 14 provides the optimal siting and sizing of capacitors obtained by the SQI-SOS as well as other methods such as SOS, SQI-SOS ${ }_{c}$, SOS $_{c}$, CSA [16], IHA [17], FPA [18], ABC [19], and MGABC [30]. Fixed and switched capacitors on the load levels are also provided in Table 14. At the load level of $100 \%$, the optimal locations obtained by the SQI-SOS are buses $32,42,50,74,80,96,107$, and 111 . The capacitors installed at those buses have optimal sizes of $1050 \mathrm{kVAr}$, $600 \mathrm{kVAr}, 1500 \mathrm{kVAr}, 1400 \mathrm{kVAr}, 1100 \mathrm{kVAr}, 800 \mathrm{kVAr}$, $900 \mathrm{kVAr}$, and $1450 \mathrm{kVAr}$, respectively.

The result comparison between the proposed SQI-SOS and other methods is represented in Table 15. The comparison shows that the SQI-SOS yields a better solution quality than SOS, CSA [16], IHA [17], FPA [18], ABC [19], and $\mathrm{MGABC}$ [30] in terms of the total annual cost. Regarding system conditions, the system without capacitor installation has a real power loss of $1298.09 \mathrm{~kW}$, minimum voltage of 0.8688 p.u., and overall power factor of 0.7998 lagging at full load level. With the installation of capacitors by the SQI-SOS, the real power loss is reduced to $847.0243 \mathrm{~kW}$, the minimum system voltage is improved to
0.9047 p.u., and the overall system power factor is enhanced to 0.9357 . The total annual cost is also decreased from $440,236.40$ \$ (uncompensated case) to $323,532.03$ \$ (compensated case) by the proposed SQI-SOS at the full load level. In this case, the original SOS settles at an annual cost objective value of $323,578.50 \$$, which is higher than the one found by the SQI-SOS. Furthermore, the standard deviation of total annual costs for 50 trial runs obtained by the SQISOS method is lower than that from the SOS method, proving that the SQI-SOS algorithm is more robust than the SOS approach in terms of the statistical performance. Figure 16 illustrates the convergence curves obtained by the SQI-SOS and SOS methods. It is obvious that the SQI-SOS approach converges to the optimum solution with less number of iterations compared to the SOS method. It shows that the convergence capacity of the SQI-SOS is better than that of the SOS. In addition, computational reliability can be verified for this system because there is no significant difference between the solution with the continuous capacitor sizing variables and the solution with the discrete ones. Another notable result is that the bus voltage profile of the system in the $100 \%$ load level is improved after the 
TABLe 9: Optimal siting and sizing of capacitors for the 69-bus system with the CP load model at different load levels.

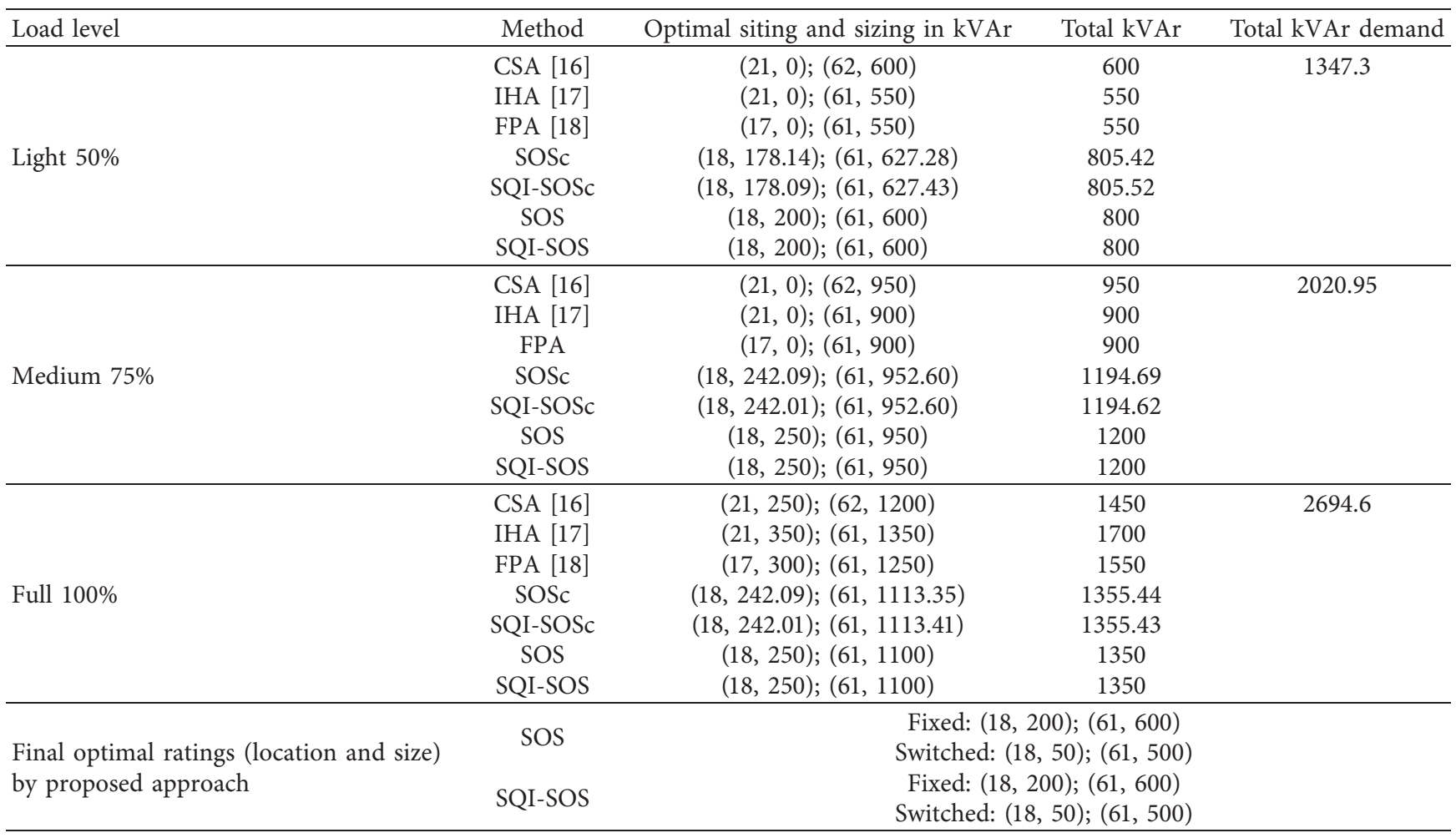

TABLE 10: Results of real power loss in all lines of the 69-bus system before and after the installation of capacitors.

\begin{tabular}{|c|c|c|}
\hline \multirow{2}{*}{ Line } & \multicolumn{2}{|c|}{ Real power loss (kW) } \\
\hline & Uncompensated & Compensated by SQI-SOS \\
\hline $1-2$ & 0.075 & 0.055 \\
\hline $2-3$ & 0.075 & 0.055 \\
\hline $3-4$ & 0.195 & 0.140 \\
\hline $4-5$ & 1.937 & 1.306 \\
\hline $5-6$ & 28.244 & 19.036 \\
\hline $6-7$ & 29.352 & 19.780 \\
\hline $7-8$ & 6.895 & 4.633 \\
\hline $8-9$ & 3.375 & 2.247 \\
\hline $9-10$ & 4.778 & 3.621 \\
\hline $10-11$ & 1.015 & 0.763 \\
\hline $11-12$ & 2.193 & 1.559 \\
\hline $12-13$ & 1.287 & 0.885 \\
\hline $13-14$ & 1.247 & 0.858 \\
\hline $14-15$ & 1.206 & 0.833 \\
\hline $15-16$ & 0.224 & 0.155 \\
\hline $16-17$ & 0.321 & 0.228 \\
\hline $17-18$ & 0.003 & 0.002 \\
\hline $18-19$ & 0.104 & 0.103 \\
\hline $19-20$ & 0.067 & 0.066 \\
\hline $20-21$ & 0.108 & 0.106 \\
\hline $21-22$ & 0.001 & 0.001 \\
\hline $22-23$ & 0.005 & 0.005 \\
\hline $23-24$ & 0.011 & 0.011 \\
\hline $24-25$ & 0.006 & 0.006 \\
\hline $25-26$ & 0.002 & 0.002 \\
\hline $26-27$ & $3.50 E-04$ & $3.44 E-04$ \\
\hline
\end{tabular}


TABle 10: Continued.

\begin{tabular}{|c|c|c|}
\hline \multirow{2}{*}{ Line } & \multicolumn{2}{|c|}{ Real power loss (kW) } \\
\hline & Uncompensated & Compensated by SQI-SOS \\
\hline $3-28$ & $3.47 E-04$ & $3.47 E-04$ \\
\hline $28-29$ & 0.003 & 0.003 \\
\hline $29-30$ & 0.006 & 0.006 \\
\hline $30-31$ & 0.001 & 0.001 \\
\hline $31-32$ & 0.005 & 0.005 \\
\hline $32-33$ & 0.012 & 0.012 \\
\hline $33-34$ & 0.010 & 0.010 \\
\hline $34-35$ & $4.79 E-04$ & $4.79 E-04$ \\
\hline $3-36$ & 0.001 & 0.001 \\
\hline $36-37$ & 0.015 & 0.015 \\
\hline $37-38$ & 0.017 & 0.017 \\
\hline $38-39$ & 0.005 & 0.005 \\
\hline $39-40$ & $1.98 E-04$ & $1.98 E-04$ \\
\hline $40-41$ & 0.049 & 0.049 \\
\hline $41-42$ & 0.020 & 0.020 \\
\hline $42-43$ & 0.003 & 0.003 \\
\hline $43-44$ & 0.001 & 0.001 \\
\hline $44-45$ & 0.006 & 0.006 \\
\hline $45-46$ & $1.26 E-05$ & $1.26 E-05$ \\
\hline $4-47$ & 0.023 & 0.023 \\
\hline $47-48$ & 0.583 & 0.583 \\
\hline $48-49$ & 1.634 & 1.633 \\
\hline $49-50$ & 0.116 & 0.116 \\
\hline $8-51$ & 0.002 & 0.002 \\
\hline $51-52$ & $4.38 E-05$ & $4.34 E-05$ \\
\hline $9-53$ & 5.781 & 3.701 \\
\hline $53-54$ & 6.711 & 4.296 \\
\hline $54-55$ & 9.125 & 5.830 \\
\hline $55-56$ & 8.790 & 5.607 \\
\hline $56-57$ & 49.685 & 31.694 \\
\hline $57-58$ & 24.489 & 15.622 \\
\hline $58-59$ & 9.506 & 6.064 \\
\hline $59-60$ & 10.671 & 6.787 \\
\hline $60-61$ & 14.026 & 8.921 \\
\hline $61-62$ & 0.112 & 0.108 \\
\hline $62-63$ & 0.135 & 0.129 \\
\hline $63-64$ & 0.661 & 0.634 \\
\hline $64-65$ & 0.041 & 0.040 \\
\hline $11-66$ & 0.003 & 0.003 \\
\hline $66-67$ & $1.53 E-05$ & $1.52 E-05$ \\
\hline $12-68$ & 0.023 & 0.023 \\
\hline $68-69$ & $3.71 E-05$ & $3.66 E-05$ \\
\hline
\end{tabular}

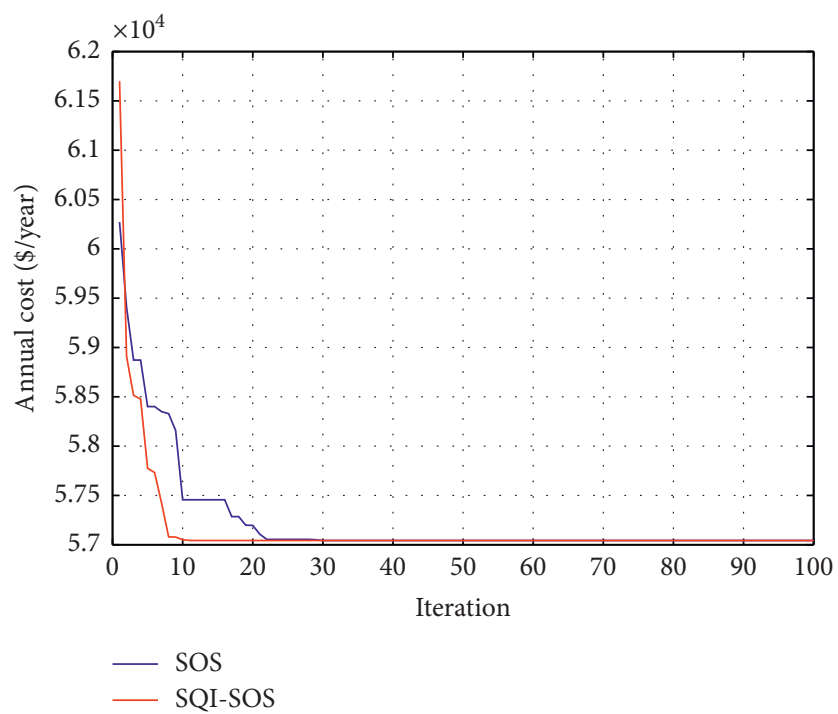

Figure 9: Convergence curves of the total cost of the 69-bus system with the CP load model at $100 \%$ loading. 


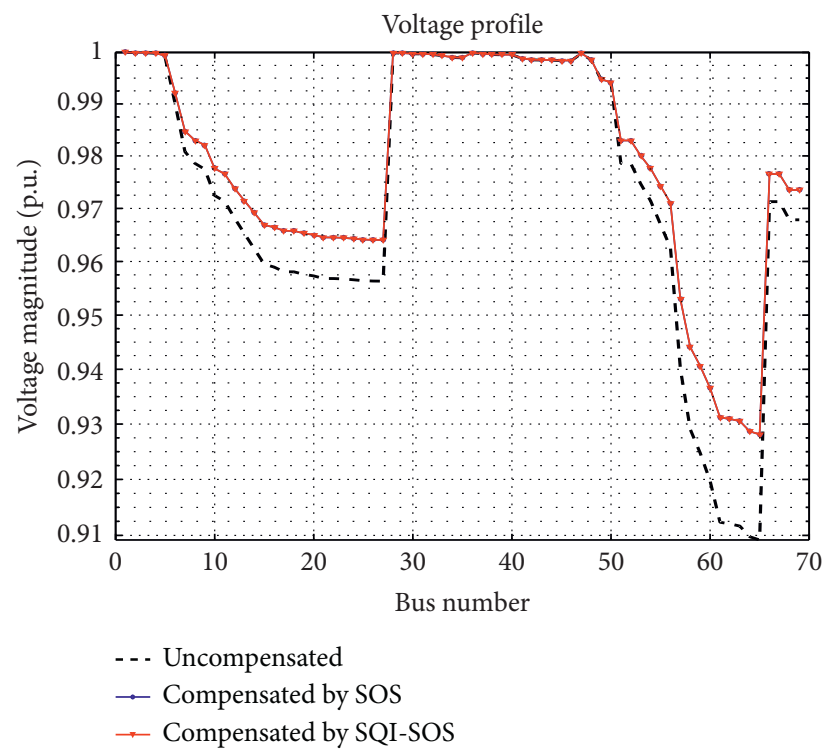

Figure 10: Voltage profile of the 69-bus system before and after compensation with the CP load model at 100\% loading.

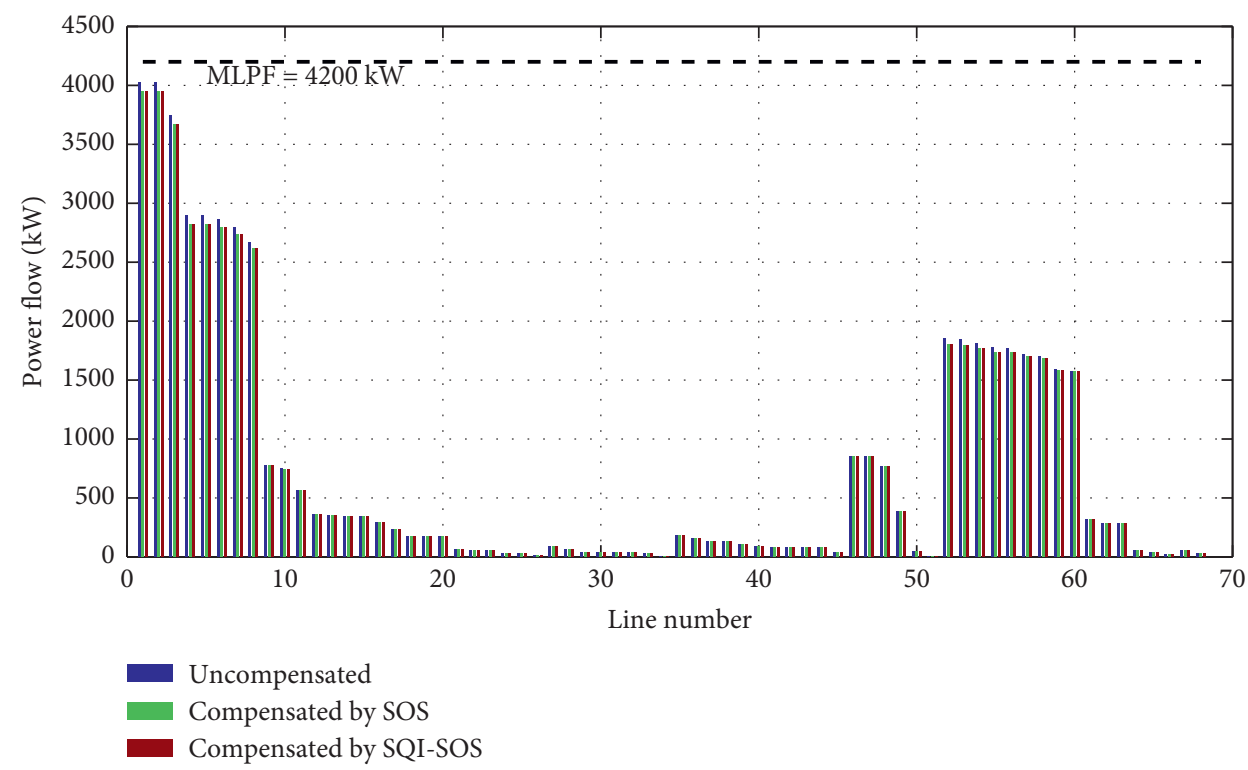

Figure 11: Comparison of lines power flow of the 69-bus system before and after compensation with the CP load model at $100 \%$ loading.

connection of capacitors by the proposed method, which is illustrated in Figure 17. In addition, the effect of capacitor placement on the lines power flow can be perceived in Figure 18. From the figure, it is clear that after the connection of capacitors results in the curtailment of MPF on $\mathrm{L}_{1-2}$. Furthermore, the power flow on most lines after compensation is lower than that before compensation. The detail of power loss comparison before and after compensation corresponding to the full load level using the SQI-SOS method in each line is given in Table 16.

To sum up, the proposed SQI-SOS reveals an outstanding performance when compared with the previous methods available in the literature in terms of the obtained minimum total annual cost. Moreover, it can be realized that the proposed SQI-SOS is more efficient and robust than the original SOS algorithm in solving the OCP problem in this scenario.

5.4.2. Scenario 2: Voltage-Dependent Load Model with Maximum Load Demand. The simulation results for the 119-bus system after compensation with the nonlinear load models are given in Table 17. It is realized that the optimal compensation by the proposed method leads to a significant improvement in the system performance indices in all the examined load models. The detailed information on the optimal capacitor locations and sizes for each load model is given in Table 18. The clustered column graph in Figure 19 
TABLE 11: Comparison results of the 69-bus system before and after compensation with the CP load model at different load levels.

\begin{tabular}{|c|c|c|c|c|c|c|c|c|c|}
\hline \multirow{2}{*}{ Load level } & \multirow{2}{*}{ Item } & \multirow{2}{*}{ Uncompensated } & \multicolumn{7}{|c|}{ Compensated } \\
\hline & & & CSA [16] & IHA [17] & FPA [18] & $\operatorname{SOS}_{\mathrm{c}}$ & SQI-SOS $_{\mathrm{c}}$ & SOS & SQI-SOS \\
\hline \multirow{4}{*}{ Light $50 \%$} & $V_{\min }$, p.u. & 0.9567 & 0.966 & 0.9652 & 0.965 & 0.9666 & 0.9666 & 0.9663 & 0.9663 \\
\hline & $\mathrm{P}_{\text {loss }}, \mathrm{kW}$ & 51.6064 & 35.89 & 35.9451 & 36.5235 & 34.3536 & 34.3536 & 34.3938 & 34.3938 \\
\hline & $\mathrm{PF}_{\text {overall }}$ & 0.8184 & 0.93 & 0.9218 & 0.9218 & 0.9608 & 0.9608 & 0.9601 & 0.9601 \\
\hline & MPF, kW & $\begin{array}{c}1952.65 \\
\left(\# L_{1-2}\right)\end{array}$ & - & - & - & $\begin{array}{c}1935.40 \\
\left(\# L_{1-2}\right)\end{array}$ & $\begin{array}{c}1935.40 \\
\left(\# L_{1-2}\right)\end{array}$ & $\begin{array}{c}1935.44 \\
\left(\# L_{1-2}\right)\end{array}$ & $\begin{array}{c}1935.44 \\
\left(\# L_{1-2}\right)\end{array}$ \\
\hline \multirow{4}{*}{ Medium $75 \%$} & $V_{\min }$, p.u. & 0.9335 & 0.9486 & 0.949 & 0.9506 & 0.9491 & 0.9491 & 0.9491 & 0.9491 \\
\hline & $\mathrm{P}_{\text {loss }}, \mathrm{kW}$ & 121.0301 & 83.19 & 82.57 & 82.5706 & 79.7548 & 79.755 & 79.7399 & 79.7399 \\
\hline & $\mathrm{PF}_{\text {overall }}$ & 0.8198 & 0.94 & 0.93 & 0.9299 & 0.9592 & 0.9592 & 0.9597 & 0.9597 \\
\hline & MPF, kW & $\begin{array}{c}2972.60 \\
\left(\# L_{1-2}\right)\end{array}$ & - & - & - & $\begin{array}{c}2931.32 \\
\left(\# L_{1-2}\right)\end{array}$ & $\begin{array}{c}2931.32 \\
\left(\# L_{1-2}\right)\end{array}$ & $\begin{array}{c}2931.31 \\
\left(\# L_{1-2}\right)\end{array}$ & $\begin{array}{c}2931.31 \\
\left(\# L_{1-2}\right)\end{array}$ \\
\hline \multirow{4}{*}{ Full 100\% } & $V_{\min }$, p.u. & 0.9092 & 0.930 & 0.937 & 0.95 & 0.9282 & 0.9282 & 0.9281 & 0.9281 \\
\hline & $\mathrm{P}_{\text {loss }}, \mathrm{kW}$ & 225.0006 & 147.95 & 145.3236 & 145.14 & 148.323 & 148.323 & 148.4248 & 148.4248 \\
\hline & $\mathrm{PF}_{\text {overall }}$ & 0.8213 & 0.95 & 0.9656 & 0.9559 & 0.9419 & 0.9419 & 0.9415 & 0.9415 \\
\hline & MPF, kW & $\begin{array}{c}4027.10 \\
\left(\# L_{1-2}\right)\end{array}$ & - & - & - & $\begin{array}{c}3950.42 \\
\left(\# L_{1-2}\right) \\
\end{array}$ & $\begin{array}{c}3950.42 \\
\left(\# L_{1-2}\right) \\
\end{array}$ & $\begin{array}{c}3950.52 \\
\left(\# L_{1-2}\right) \\
\end{array}$ & $\begin{array}{c}3950.52 \\
\left(\# L_{1-2}\right) \\
\end{array}$ \\
\hline \multirow{2}{*}{\multicolumn{2}{|c|}{$\begin{array}{l}\text { Total annual cost (\$/year) } \\
\text { Annual net savings } \\
\text { (\$/year) }\end{array}$}} & $76,349.9$ & $58,074.59$ & $58,165.60$ & $57,753.11$ & $57,035.52$ & $57,035.52$ & $57,043.14$ & $57,043.14$ \\
\hline & & - & $18,275.31$ & $18,184.30$ & $18,596.79$ & $19,314.37$ & $19,314.37$ & $19,306.75$ & $19,306.75$ \\
\hline \multicolumn{2}{|c|}{ Worst cost (\$/year) } & - & - & - & - & $57,035.64$ & $57,035.52$ & $57,043.61$ & $57,043.14$ \\
\hline \multicolumn{2}{|c|}{ Best cost (\$/year) } & - & - & - & - & $57,035.52$ & $57,035.52$ & $57,043.14$ & $57,043.14$ \\
\hline \multicolumn{2}{|c|}{ Mean cost (\$/year) } & - & - & - & - & $57,035.53$ & 57035.52 & $57,043.15$ & $57,043.14$ \\
\hline \multicolumn{2}{|c|}{ Standard deviation $(\sigma)$} & - & - & - & - & 0.0167 & 0.0 & 0.0657 & $6.54 \cdot 10^{-11}$ \\
\hline
\end{tabular}

TABLE 12: Comparative results of the 69-bus system after compensation with different load models.

\begin{tabular}{|c|c|c|c|c|}
\hline \multirow{2}{*}{ Load type } & \multirow{2}{*}{ Item } & \multirow{2}{*}{ Uncompensated } & \multicolumn{2}{|c|}{ Compensated } \\
\hline & & & SOS & SQI-SOS \\
\hline \multirow{6}{*}{ Industrial load } & $V_{\min }$ (bus) & $0.9187(65)$ & $0.9304(65)$ & $0.9304(65)$ \\
\hline & $\mathrm{P}_{\text {loss }}, \mathrm{kW}$ & 175.0872 & 143.121 & 143.121 \\
\hline & $\mathrm{PF}_{\text {overall }}$ & 0.8752 & 0.9538 & 0.9538 \\
\hline & Total cost, \$/year & $92,025.82$ & $82,174.39$ & $82,174.39$ \\
\hline & Annual savings (\$/year) & - & $9,851.42$ & $9,851.42$ \\
\hline & MPF, kW & $\begin{array}{c}3,946.63 \\
\left(\# L_{1-2}\right)\end{array}$ & $\begin{array}{c}3,919.18 \\
\left(\# L_{1-2}\right)\end{array}$ & $\begin{array}{c}3,919.18 \\
\left(\# L_{1-2}\right)\end{array}$ \\
\hline \multirow{6}{*}{ Residential load } & $V_{\min }$ (bus) & $0.9203(65)$ & $0.9335(65)$ & $0.9335(65)$ \\
\hline & $\mathrm{P}_{\text {loss }}, \mathrm{kW}$ & 170.8264 & 131.1693 & 131.1693 \\
\hline & $\mathrm{PF}_{\text {overall }}$ & 0.8516 & 0.9497 & 0.9497 \\
\hline & Total cost, \$/year & $89,786.35$ & $75,892.56$ & $75,892.56$ \\
\hline & Annual savings (\$/year) & - & $13,893.79$ & $13,893.79$ \\
\hline & MPF, kW & $\begin{array}{c}3,823.35 \\
\left(\# L_{1-2}\right) \\
\end{array}$ & $\begin{array}{c}3,808.35 \\
\left(\# L_{1-2}\right) \\
\end{array}$ & $\begin{array}{c}3,808.35 \\
\left(\# L_{1-2}\right)\end{array}$ \\
\hline \multirow{6}{*}{ Commercial load } & $V_{\min }$ (bus) & $0.9222(65)$ & $0.9351(65)$ & $0.9351(65)$ \\
\hline & $\mathrm{P}_{\text {loss }}, \mathrm{kW}$ & 165.0464 & 123.2511 & 123.2511 \\
\hline & $\mathrm{PF}_{\text {overall }}$ & 0.8393 & 0.9442 & 0.9442 \\
\hline & Total cost, \$/year & $86,748.37$ & $71,580.75$ & $71,580.75$ \\
\hline & Annual savings (\$/year) & - & $15,167.61$ & $15,167.61$ \\
\hline & MPF, kW & $\begin{array}{c}3,731.56 \\
\left(\# L_{1-2}\right)\end{array}$ & $\begin{array}{c}3,728.19 \\
\left(\# L_{1-2}\right)\end{array}$ & $\begin{array}{c}3,728.19 \\
\left(\# L_{1-2}\right)\end{array}$ \\
\hline \multirow{6}{*}{ Mixed load } & $V_{\min }$ (bus) & $0.9199(65)$ & $0.9325(65)$ & $0.9325(65)$ \\
\hline & $\mathrm{P}_{\text {loss }}, \mathrm{kW}$ & 171.3912 & 134.9734 & 134.9734 \\
\hline & $\mathrm{PF}_{\text {overall }}$ & 0.8606 & 0.9512 & 0.9512 \\
\hline & Total cost, \$/year & $90,083.21$ & $77,892.02$ & $77,892.02$ \\
\hline & Annual savings (\$/year) & - & $12,191.18$ & $12,191.18$ \\
\hline & MPF, kW & $\begin{array}{c}3,863.60 \\
\left(\# L_{1-2}\right)\end{array}$ & $\begin{array}{c}3,844.38 \\
\left(\# L_{1-2}\right)\end{array}$ & $\begin{array}{c}3,844.38 \\
\left(\# L_{1-2}\right)\end{array}$ \\
\hline
\end{tabular}


Annual cost (000s dollars/year)

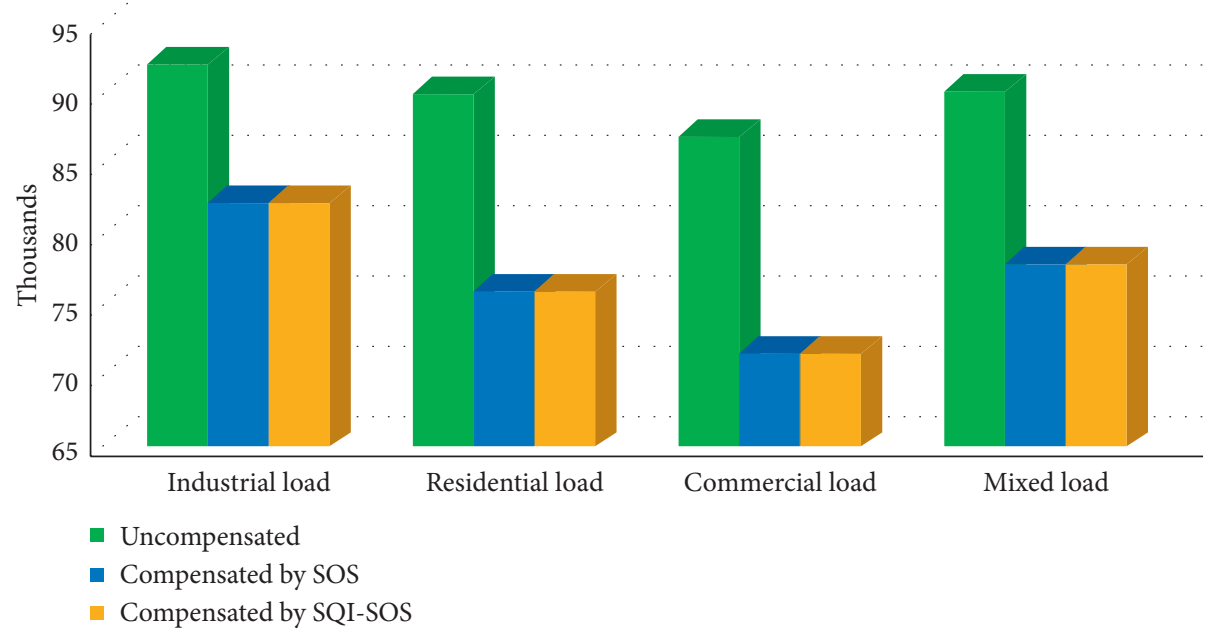

Figure 12: Annual cost of the 69-bus system before and after compensation with different load models.

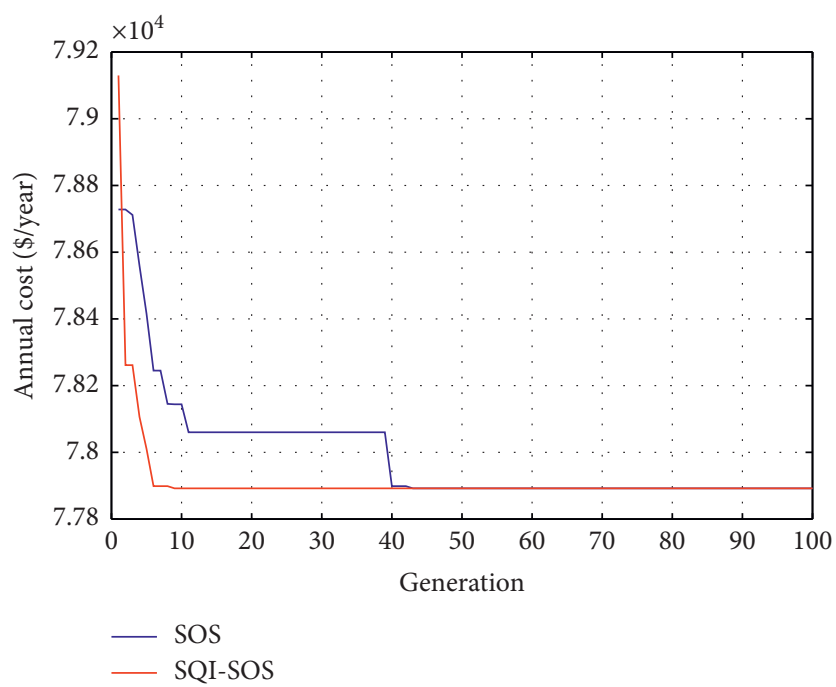

Figure 13: Convergence curves of the total cost of the 69-bus system with the mixed load model.

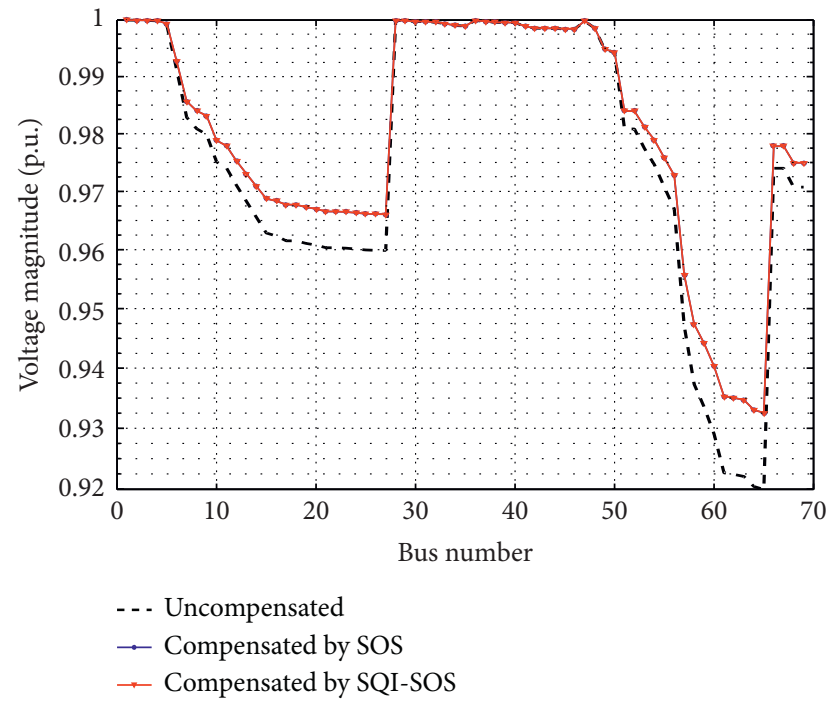

Figure 14: Voltage profile of the 69-bus system before and after compensation with the mixed load model. 


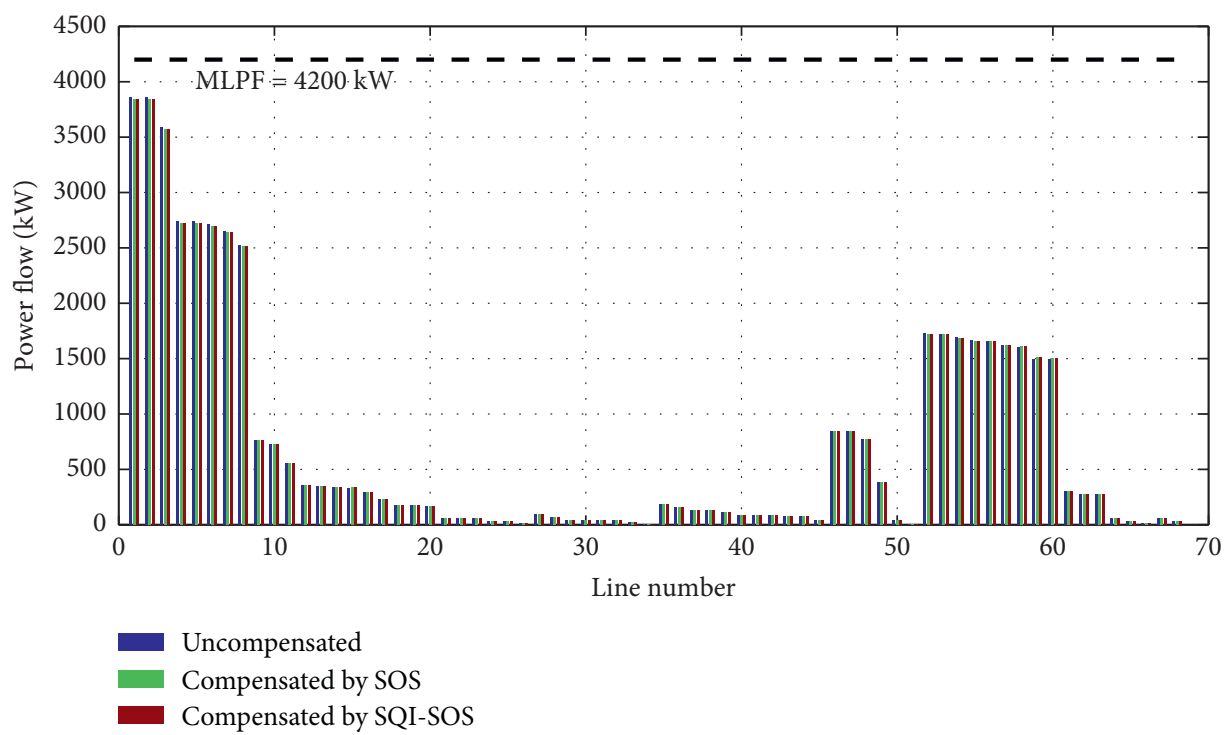

FIgURE 15: Comparison of lines power flow of the 69-bus system before and after compensation with the mixed load model.

TABLE 13: Optimal locations and sizes of capacitors for the 69-bus system with different load models.

\begin{tabular}{lccc}
\hline Load type & Locations and injected kVArs & Total kVAr & Method \\
\hline Industrial load & $(18,300) ;(61,1150)$ & 1450 & SOS \\
& $(18,300) ;(61,1150)$ & 1450 & SQI-SOS \\
Residential load & $(18,300) ;(61,1150)$ & 1450 & SOS \\
& $(18,300) ;(61,1150)$ & 1400 & SQI-SOS \\
Commercial load & $(18,300) ;(61,1100)$ & 1400 & SOS \\
Mixed load & $(18,300) ;(61,1100)$ & 1450 & SQI-SOS \\
& $(18,300) ;(61,1150)$ & 1450 & SOS \\
\hline
\end{tabular}

TABLE 14: Optimal siting and sizing of capacitors for the 119-bus system with the CP load model at different load levels.

\begin{tabular}{|c|c|c|c|c|c|c|c|c|c|}
\hline \multirow{2}{*}{$\begin{array}{l}\text { Item } \\
\text { Method }\end{array}$} & \multicolumn{9}{|c|}{ Load level-light $50 \%$} \\
\hline & CSA [16] & IHA [17] & FPA [18] & $\mathrm{ABC}[19]$ & $\begin{array}{c}\text { MGABC } \\
{[30]}\end{array}$ & $\mathrm{SOS}_{\mathrm{c}}$ & $\mathrm{SQI}^{-\mathrm{SOS}_{\mathrm{c}}}$ & SOS & SQI-SOS \\
\hline \multirow{15}{*}{ Locations (kVArs) } & $32(0)$ & $39(1200)$ & $32(0)$ & $32(500)$ & $33(300)$ & $96(561.52)$ & $50(977.53)$ & $42(400)$ & $32(850)$ \\
\hline & $39(1100)$ & $43(0)$ & $40(1100)$ & $35(0)$ & $35(750)$ & $107(636.82)$ & $96(548.25)$ & $111(750)$ & $80(800)$ \\
\hline & $40(0)$ & $70(900)$ & $70(750)$ & $40(0)$ & $45(300)$ & $80(807.44)$ & $32(899.34)$ & $80(800)$ & $74(750)$ \\
\hline & $70(350)$ & $74(0)$ & $74(1100)$ & $50(0)$ & $46(150)$ & $50(982.00)$ & $80(811.47)$ & $74(750)$ & $111(800)$ \\
\hline & $74(500)$ & $86(0)$ & $89(500)$ & $70(0)$ & $49(900)$ & $74(753.84)$ & $107(626.67)$ & $96(550)$ & $96(550)$ \\
\hline & $86(450)$ & $91(600)$ & $104(0)$ & $73(750)$ & $54(450)$ & $42(393.18)$ & $42(392.52)$ & $107(600)$ & $107(550)$ \\
\hline & $108(0)$ & $107(0)$ & $109(0)$ & $79(500)$ & $71(750)$ & $32(904.33)$ & $111(733.85)$ & $50(950)$ & $50(1000)$ \\
\hline & $118(1000)$ & $109(0)$ & $112(0)$ & $105(300)$ & $76(150)$ & $111(753.84)$ & $74(751.84)$ & $33(750)$ & $42(400)$ \\
\hline & & $118(1000)$ & $118(1000)$ & $106(0)$ & $86(750)$ & & & & \\
\hline & & & & $109(0)$ & $94(300)$ & & & & \\
\hline & & & & $110(950)$ & $101(750)$ & & & & \\
\hline & & & & & $110(600)$ & & & & \\
\hline & & & & & $111(450)$ & & & & \\
\hline & & & & & $114(150)$ & & & & \\
\hline & & & & & $115(150)$ & & & & \\
\hline Total kVAr & 3400 & 3700 & 3350 & 3900 & 6900 & 5777.11 & 5741.51 & 5550 & 5700 \\
\hline Total kVAr demand & 8520.55 & & & & & & & & \\
\hline \multicolumn{10}{|c|}{ Load level-medium $75 \%$} \\
\hline
\end{tabular}


Table 14: Continued.

\begin{tabular}{|c|c|c|c|c|c|c|c|c|c|}
\hline \multirow{2}{*}{$\begin{array}{l}\text { Item } \\
\text { Method }\end{array}$} & \multicolumn{9}{|c|}{ Load level-light $50 \%$} \\
\hline & CSA [16] & IHA [17] & FPA [18] & $\mathrm{ABC}[19]$ & $\begin{array}{c}\text { MGABC } \\
{[30]}\end{array}$ & $\operatorname{SOS}_{\mathrm{c}}$ & SQI-SOS $_{\mathrm{c}}$ & SOS & SQI-SOS \\
\hline \multirow{15}{*}{ Locations (kVArs) } & $32(900)$ & $39(1500)$ & $32(0)$ & $32(0)$ & $33(600)$ & $96(804.70)$ & $50(1499.95)$ & $42(550)$ & $32(1050)$ \\
\hline & $39(1500)$ & $43(0)$ & $40(1500)$ & $35(800)$ & $35(1200)$ & $107(903.13)$ & $96(820.33)$ & $111(1100)$ & $80(1100)$ \\
\hline & $40(0)$ & $70(900)$ & $70(750)$ & $40(1200)$ & $45(300)$ & $80(1107.43)$ & $32(1137.43)$ & $80(1100)$ & $74(1150)$ \\
\hline & $70(600)$ & $74(600)$ & $74(600)$ & $50(450)$ & $46(150)$ & $50(1497.64)$ & $80(1087.39)$ & $74(1150)$ & $111(1150)$ \\
\hline & $74(750)$ & $86(0)$ & $89(1500)$ & $70(550)$ & $49(1350)$ & $74(1146.86)$ & $107(904.62)$ & $96(800)$ & $96(800)$ \\
\hline & $86(700)$ & $91(1500)$ & $104(0)$ & $73(750)$ & $54(750)$ & $42(553.04)$ & $42(556.16)$ & $107(950)$ & $107(900)$ \\
\hline & $108(750)$ & $107(0)$ & $109(0)$ & $79(850)$ & $71(1050)$ & $32(1122.45)$ & $111(1132.41)$ & $50(1500)$ & $50(1500)$ \\
\hline & $118(1100)$ & $109(0)$ & $112(0)$ & $105(0)$ & $76(300)$ & $111(1133.50)$ & $74(1145.73)$ & $33(1000)$ & $42(600)$ \\
\hline & & $118(1200)$ & $118(1000)$ & $106(0)$ & $86(1050)$ & & & & \\
\hline & & & & $109(800)$ & $94(450)$ & & & & \\
\hline & & & & $110(1000)$ & $101(1200)$ & & & & \\
\hline & & & & & $110(900)$ & & & & \\
\hline & & & & & $111(600)$ & & & & \\
\hline & & & & & $114(150)$ & & & & \\
\hline & & & & & $115(150)$ & & & & \\
\hline \multirow{2}{*}{$\begin{array}{l}\text { Total kVAr } \\
\text { Total kVAr demand }\end{array}$} & 6300 & 5700 & 5350 & 6400 & 10200 & 8268.79 & 8284.06 & 8150 & 8250 \\
\hline & 12780.83 & & & & & & & & \\
\hline \multicolumn{10}{|c|}{ Load level-full $100 \%$} \\
\hline \multirow{15}{*}{ Locations (kVArs) } & $32(1500)$ & $39(1500)$ & $32(1500)$ & $32(850)$ & $33(900)$ & $96(804.85)$ & $50(1499.95)$ & $42(550)$ & $32(1050)$ \\
\hline & $39(1500)$ & $43(1000)$ & $40(1500)$ & $35(1050)$ & $35(1500)$ & $107(903.63)$ & $96(820.46)$ & $111(1400)$ & $80(1100)$ \\
\hline & $40(550)$ & $70(1000)$ & $70(850)$ & $40(1300)$ & $45(450)$ & $80(1107.66)$ & $32(1137.43)$ & $80(1100)$ & $74(1400)$ \\
\hline & $70(950)$ & $74(1000)$ & $74(1100)$ & $50(800)$ & $46(450)$ & $50(1499.53)$ & $80(1087.45)$ & $74(1400)$ & $111(1450)$ \\
\hline & $74(750)$ & $86(900)$ & $89(1500)$ & $70(550)$ & $49(1500)$ & $74(1395.53)$ & $107(904.64)$ & $96(800)$ & $96(800)$ \\
\hline & $86(1050)$ & $91(1500)$ & $104(500)$ & $73(1300)$ & $54(1050)$ & $42(553.16)$ & $42(556.20)$ & $107(950)$ & $107(900)$ \\
\hline & $108(1500)$ & $107(850)$ & $109(900)$ & 79 (1200) & $71(1200)$ & $32(1122.81)$ & $111(1435.61)$ & $50(1500)$ & $50(1500)$ \\
\hline & $118(1200)$ & $109(850)$ & $112(250)$ & $105(700)$ & $76(450)$ & $111(1436.75)$ & $74(1408.13)$ & $33(1000)$ & $42(600)$ \\
\hline & & $118(1200)$ & $118(1150)$ & $106(250)$ & $86(1350)$ & & & & \\
\hline & & & & $109(800)$ & $94(750)$ & & & & \\
\hline & & & & $110(1200)$ & $101(1500)$ & & & & \\
\hline & & & & & $110(1350)$ & & & & \\
\hline & & & & & $111(750)$ & & & & \\
\hline & & & & & $114(150)$ & & & & \\
\hline & & & & & $115(150)$ & & & & \\
\hline \multirow{2}{*}{$\begin{array}{l}\text { Total kVAr } \\
\text { Total kVAr demand }\end{array}$} & 9000 & 9800 & 9250 & 10000 & 13500 & 8823.94 & 8849.91 & 8700 & 8800 \\
\hline & & & & & 17041.1 & & & & \\
\hline \multirow{2}{*}{ Fixed capacitors } & SOS & \multirow{4}{*}{\multicolumn{8}{|c|}{$\begin{array}{l}(42,400) ;(111,750) ;(80,800) ;(74,750) ;(96,550) ;(107,600) ;(50,950) ;(33,750) \\
(32,850) ;(80,800) ;(74,750) ;(111,800) ;(96,550) ;(107,550) ;(50,1000) ;(42,400) \\
(42,150) ;(111,650) ;(80,300) ;(74,650) ;(96,250) ;(107,350) ;(50,550) ;(33,250) \\
(32,200) ;(80,300) ;(74,650) ;(111,650) ;(96,250) ;(107,350) ;(50,500) ;(42,200)\end{array}$}} \\
\hline & SQI-SOS & & & & & & & & \\
\hline \multirow{2}{*}{ Switched capacitors } & SOS & & & & & & & & \\
\hline & SQI-SOS & & & & & & & & \\
\hline
\end{tabular}

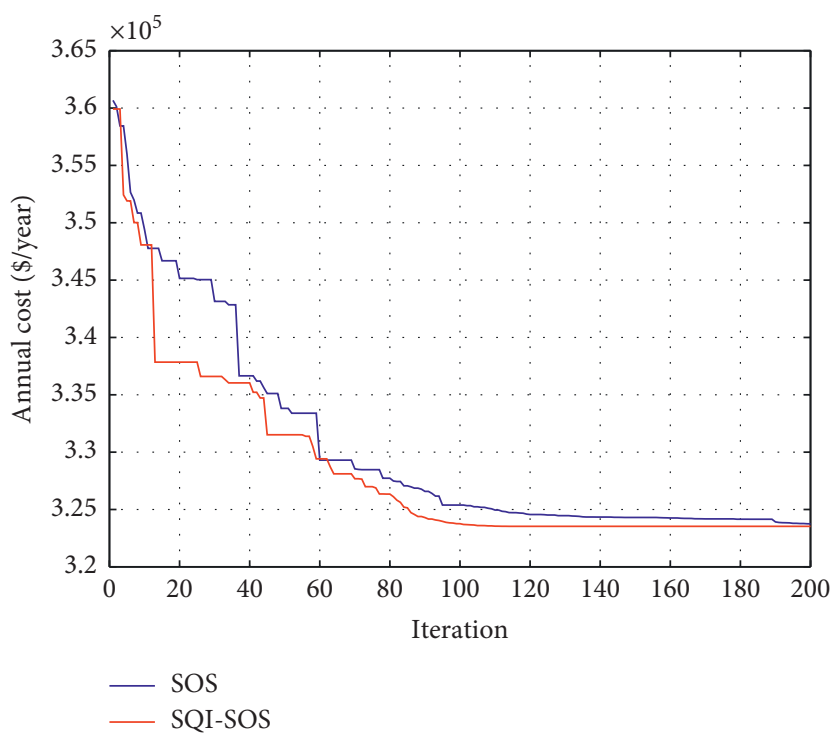

FIgURE 16: Convergence curves of the total cost of the 119-bus system with the CP load model at $100 \%$ loading. 


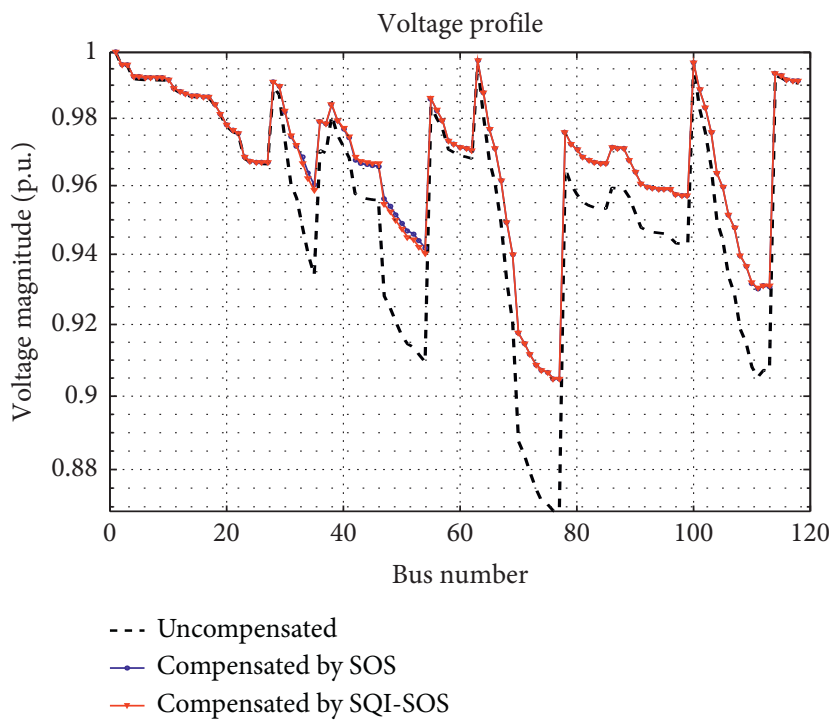

Figure 17: Voltage profile of the 119-bus system before and after compensation with the CP load model at $100 \%$ loading.

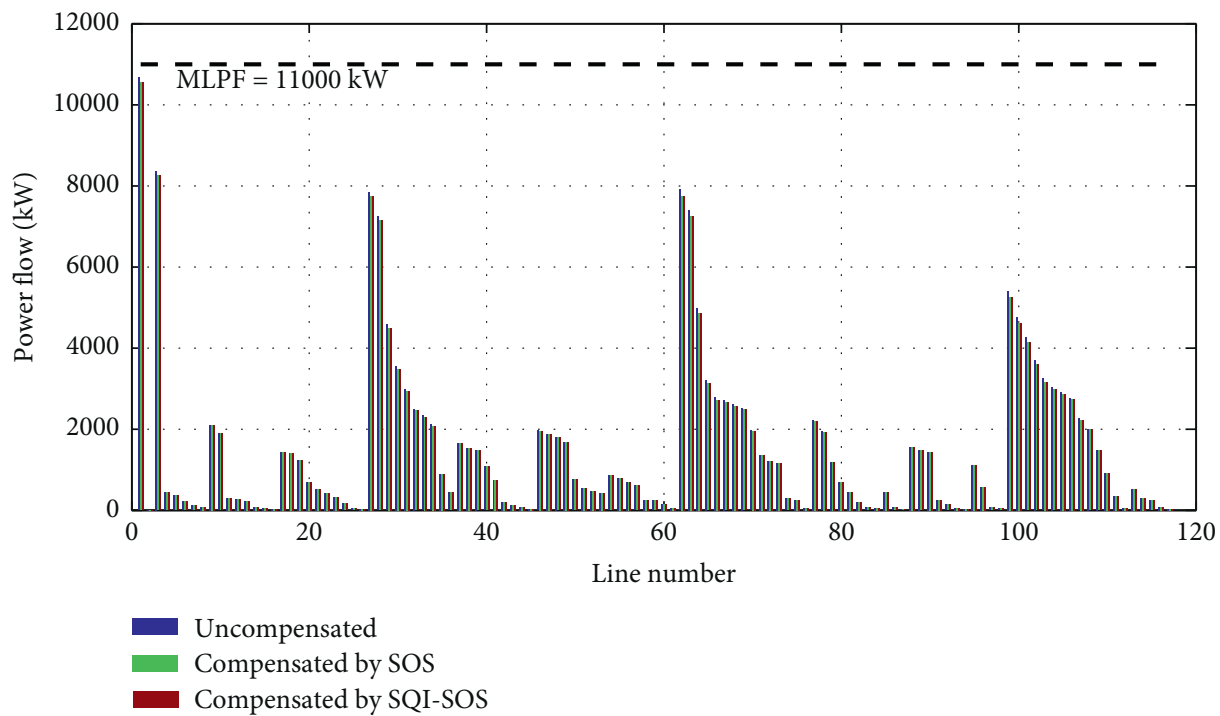

FIGURE 18: Comparison of lines power flow of the 119-bus system before and after compensation with the CP load model at $100 \%$ loading.

shows the difference in the system annual cost before and after capacitor allocations. In the actual mixed load model, according to the proposed SQI-SOS, the shunt capacitors are placed at buses $\{32,41,50,74,80,96,108$, $111\}$ with respective sizes of $\{1400,900,1500,1350,1200$, $900,1250,1050\} \mathrm{kVAr}$. The system parameters for the compensated case such as annual cost, real power loss, minimum system voltage, and overall power factor are remarkably enhanced to $441,643.41 \$ /$ year, $765.9692 \mathrm{~kW}$, 0.9104 p.u., and 0.9522 lagging from 514,676.09 \$/year, $979.2163 \mathrm{~kW}, 0.8905$ p.u., and 0.8464 lagging for the uncompensated case. The optimal capacitor allocations by the SQI-SOS lead to a net savings of 73,032.68 \$/year. In comparison with the SOS, the solution quality obtained by the SQI-SOS is better due to the gain of lower minimum total costs. Furthermore, the solution for OCP in this load model attained by the SQI-SOS contributes to a better improvement in the system indices as compared to the one attained by the SOS. In addition, Figure 20 discloses that the SQI-SOS has a better convergence profile than the SOS. Moreover, a marked improvement in the system voltage profile after capacitor allocation can be observed in Figure 21. Also, the change on lines power flow for the cases without capacitors and with capacitors is demonstrated in Figure 22. It is observed that after the penetration of capacitors into the system, the MPF on $\mathrm{L}_{1-2}$ is reduced to $10,344.84 \mathrm{~kW}$ as compared to $10,360.30 \mathrm{~kW}$ for the case without capacitors. Besides, the power flow on most lines is also improved after compensation. In summary, the proposed SQI-SOS again shows the ability to cope effectively with the nonlinear load models when applied to the large-scale distribution system. 


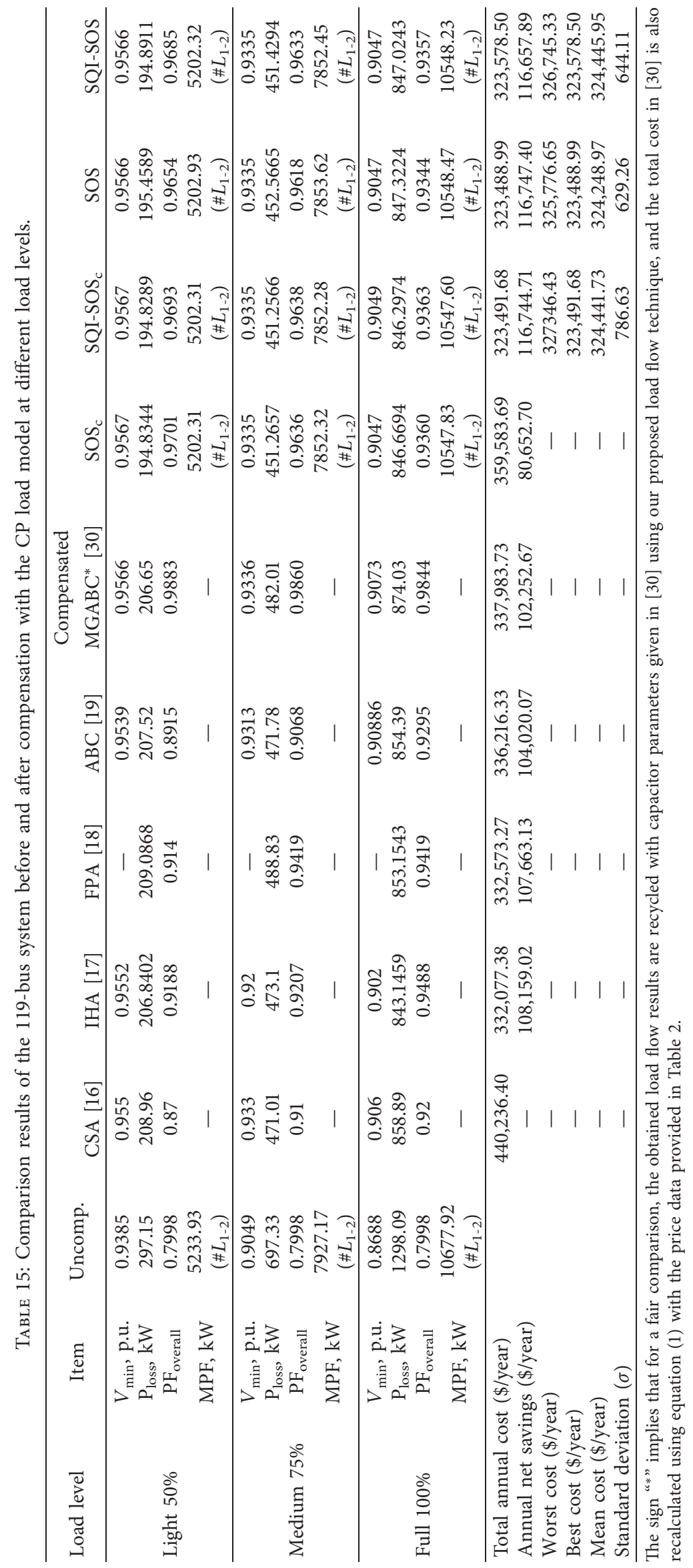


TABLE 16: Results of real power loss in all lines of the 119-bus system before and after the installation of capacitors.

\begin{tabular}{|c|c|c|}
\hline \multirow{2}{*}{ Line } & \multicolumn{2}{|c|}{ Real power loss (kW) } \\
\hline & Uncompensated & Compensated by SQI-SOS \\
\hline $1-2$ & 54.693 & 40.757 \\
\hline $2-3$ & $1.07 E-04$ & $1.07 E-04$ \\
\hline $2-4$ & 43.480 & 30.111 \\
\hline $4-5$ & 0.032 & 0.032 \\
\hline $5-6$ & 0.021 & 0.021 \\
\hline $6-7$ & 0.008 & 0.008 \\
\hline $7-8$ & 0.003 & 0.003 \\
\hline $8-9$ & 0.002 & 0.002 \\
\hline $2-10$ & 9.016 & 9.009 \\
\hline $10-11$ & 5.060 & 5.056 \\
\hline $11-12$ & 0.242 & 0.242 \\
\hline $12-13$ & 0.155 & 0.155 \\
\hline $13-14$ & 0.141 & 0.140 \\
\hline $14-15$ & 0.018 & 0.018 \\
\hline $15-16$ & 0.010 & 0.010 \\
\hline $16-17$ & 0.002 & 0.002 \\
\hline $11-18$ & 5.692 & 5.687 \\
\hline $18-19$ & 2.999 & 2.997 \\
\hline $19-20$ & 3.288 & 3.286 \\
\hline $20-21$ & 0.829 & 0.829 \\
\hline $21-22$ & 0.439 & 0.439 \\
\hline $22-23$ & 3.596 & 3.593 \\
\hline $23-24$ & 0.516 & 0.516 \\
\hline $24-25$ & 0.080 & 0.080 \\
\hline $25-26$ & 0.007 & 0.007 \\
\hline $26-27$ & 0.002 & 0.002 \\
\hline $4-28$ & 13.066 & 8.854 \\
\hline $28-29$ & 8.888 & 5.880 \\
\hline $29-30$ & 37.661 & 22.342 \\
\hline $30-31$ & 40.934 & 22.299 \\
\hline $31-32$ & 17.805 & 9.099 \\
\hline $32-33$ & 18.523 & 10.325 \\
\hline $33-34$ & 16.343 & 8.905 \\
\hline $34-35$ & 12.331 & 6.343 \\
\hline $30-36$ & 2.083 & 2.046 \\
\hline $36-37$ & 0.348 & 0.342 \\
\hline 29-38 & 11.434 & 8.464 \\
\hline $38-39$ & 9.456 & 6.855 \\
\hline $39-40$ & 3.689 & 2.654 \\
\hline $40-41$ & 4.037 & 2.855 \\
\hline $41-42$ & 7.621 & 6.211 \\
\hline $42-43$ & 0.263 & 0.257 \\
\hline $43-44$ & 0.064 & 0.063 \\
\hline $44-45$ & 0.028 & 0.028 \\
\hline $45-46$ & 0.005 & 0.005 \\
\hline $35-47$ & 15.022 & 7.490 \\
\hline $47-48$ & 8.107 & 3.970 \\
\hline $48-49$ & 9.464 & 4.546 \\
\hline $49-50$ & 8.580 & 3.956 \\
\hline $50-51$ & 2.016 & 1.887 \\
\hline $51-52$ & 0.525 & 0.492 \\
\hline $52-53$ & 1.340 & 1.254 \\
\hline $53-54$ & 1.086 & 1.017 \\
\hline $29-55$ & 4.162 & 4.140 \\
\hline $55-56$ & 3.834 & 3.815 \\
\hline $56-57$ & 2.957 & 2.941 \\
\hline $57-58$ & 4.074 & 4.053 \\
\hline 58-59 & 0.329 & 0.327 \\
\hline
\end{tabular}

TABLE 16: Continued.

\begin{tabular}{|c|c|c|}
\hline \multirow{2}{*}{ Line } & \multicolumn{2}{|c|}{ Real power loss (kW) } \\
\hline & Uncompensated & Compensated by SQI-SOS \\
\hline $59-60$ & 0.275 & 0.274 \\
\hline $60-61$ & 0.081 & 0.081 \\
\hline $61-62$ & 0.014 & 0.014 \\
\hline $1-63$ & 21.514 & 14.882 \\
\hline $63-64$ & 78.020 & 53.567 \\
\hline $64-65$ & 76.194 & 52.927 \\
\hline $65-66$ & 26.431 & 18.290 \\
\hline $66-67$ & 37.674 & 25.135 \\
\hline $67-68$ & 48.439 & 32.331 \\
\hline $68-69$ & 37.607 & 24.970 \\
\hline $69-70$ & 84.702 & 55.975 \\
\hline $70-71$ & 9.090 & 6.320 \\
\hline $71-72$ & 8.740 & 6.211 \\
\hline $72-73$ & 7.149 & 5.446 \\
\hline $73-74$ & 4.499 & 3.497 \\
\hline $74-75$ & 0.313 & 0.289 \\
\hline $75-76$ & 0.613 & 0.565 \\
\hline $76-77$ & 0.009 & 0.008 \\
\hline $64-78$ & 37.404 & 24.564 \\
\hline $78-79$ & 9.678 & 6.266 \\
\hline $79-80$ & 3.949 & 2.301 \\
\hline $80-81$ & 1.822 & 1.773 \\
\hline $81-82$ & 0.461 & 0.449 \\
\hline $82-83$ & 0.152 & 0.148 \\
\hline $83-84$ & 0.019 & 0.018 \\
\hline $84-85$ & 0.005 & 0.005 \\
\hline $79-86$ & 0.419 & 0.409 \\
\hline $86-87$ & 0.011 & 0.011 \\
\hline $87-88$ & 0.001 & 0.001 \\
\hline $65-89$ & 20.677 & 14.298 \\
\hline $89-90$ & 7.558 & 5.200 \\
\hline $90-91$ & 7.180 & 4.964 \\
\hline $91-92$ & 0.291 & 0.283 \\
\hline $92-93$ & 0.103 & 0.100 \\
\hline 93-94 & 0.022 & 0.021 \\
\hline $94-95$ & 0.022 & 0.021 \\
\hline $91-96$ & 2.974 & 2.224 \\
\hline $96-97$ & 0.917 & 0.890 \\
\hline $97-98$ & 0.012 & 0.012 \\
\hline $98-99$ & 0.002 & 0.002 \\
\hline $1-100$ & 24.074 & 15.852 \\
\hline $100-101$ & 45.611 & 28.730 \\
\hline $101-102$ & 33.412 & 20.393 \\
\hline $102-103$ & 43.442 & 25.825 \\
\hline 103-104 & 69.359 & 38.948 \\
\hline 104-105 & 22.986 & 12.902 \\
\hline $105-106$ & 43.600 & 24.262 \\
\hline $106-107$ & 19.223 & 10.705 \\
\hline $107-108$ & 31.590 & 18.174 \\
\hline 108-109 & 11.153 & 6.153 \\
\hline $109-110$ & 15.047 & 7.897 \\
\hline $110-111$ & 4.069 & 2.678 \\
\hline $110-112$ & 0.409 & 0.388 \\
\hline $112-113$ & 0.011 & 0.010 \\
\hline $100-114$ & 2.160 & 2.157 \\
\hline $114-115$ & 0.210 & 0.210 \\
\hline $115-116$ & 0.248 & 0.248 \\
\hline $116-117$ & 0.031 & 0.031 \\
\hline $117-118$ & 0.006 & 0.006 \\
\hline
\end{tabular}


TABLE 17: Comparative results of the 119-bus system after compensation with the different load models.

\begin{tabular}{|c|c|c|c|c|}
\hline \multirow{2}{*}{ Load type } & \multirow{2}{*}{ Item } & \multirow{2}{*}{ Uncompensated } & \multicolumn{2}{|c|}{ Compensated } \\
\hline & & & SOS & SQI-SOS \\
\hline \multirow{6}{*}{ Industrial load } & $V_{\min }$ (bus) & $0.8888(77)$ & $0.9069(77)$ & $0.9081(77)$ \\
\hline & $\mathrm{P}_{\text {loss }}, \mathrm{kW}$ & 996.4081 & 804.7756 & 802.4568 \\
\hline & $\mathrm{PF}_{\text {overall }}$ & 0.8627 & 0.9564 & 0.9581 \\
\hline & Total cost, \$/year & $523,712.09$ & $462,490.07$ & $461,721.30$ \\
\hline & Annual savings (\$/year) & - & $61,222.01$ & $61,990.79$ \\
\hline & MPF, kW & $\begin{array}{c}10,532.80 \\
\left(\# L_{1-2}\right)\end{array}$ & $\begin{array}{c}10,483.41 \\
\left(\# L_{1-2}\right)\end{array}$ & $\begin{array}{c}10,480.68 \\
\left(\# L_{1-2}\right)\end{array}$ \\
\hline \multirow{6}{*}{ Residential load } & $\mathrm{V}_{\min }$ (bus) & $0.8910(77)$ & $0.9121(77)$ & $0.9121(77)$ \\
\hline & $\mathrm{P}_{\text {loss }}, \mathrm{kW}$ & 977.8818 & 755.8888 & 753.3145 \\
\hline & $\mathrm{PF}_{\text {overall }}$ & 0.8361 & 0.9393 & 0.9426 \\
\hline & Total cost, \$/year & $513,974.67$ & $433,645.15$ & $433,042.09$ \\
\hline & Annual savings (\$/year) & - & $80,329.51$ & $80,932.57$ \\
\hline & MPF, kW & $\begin{array}{c}10,273.71 \\
\left(\# L_{1-2}\right)\end{array}$ & $\begin{array}{c}10,273.42 \\
\left(\# L_{1-2}\right)\end{array}$ & $\begin{array}{c}10,272.36 \\
\left(\# L_{1-2}\right)\end{array}$ \\
\hline \multirow{6}{*}{ Commercial load } & $V_{\min }$ (bus) & $0.8939(77)$ & $0.9139(77)$ & $0.9148(77)$ \\
\hline & $\mathrm{P}_{\text {loss }}, \mathrm{kW}$ & 948.3656 & 748.8654 & 738.5942 \\
\hline & $\mathrm{PF}_{\text {overall }}$ & 0.8222 & 0.9244 & 0.9356 \\
\hline & Total cost, \$/year & $498,460.96$ & $426,653.67$ & $423,805.13$ \\
\hline & Annual savings (\$/year) & - & $71,807.28$ & $74,655.83$ \\
\hline & MPF, kW & $\begin{array}{c}10,069.95 \\
\left(\# L_{1-2}\right)\end{array}$ & $\begin{array}{c}10,069.89 \\
\left(\# L_{1-2}\right)\end{array}$ & $\begin{array}{c}10,069.86 \\
\left(\# L_{1-2}\right)\end{array}$ \\
\hline \multirow{6}{*}{ Mixed load } & $V_{\min }$ (bus) & $0.8905(77)$ & $0.9103(77)$ & $0.9104(77)$ \\
\hline & $\mathrm{P}_{\text {loss }}, \mathrm{kW}$ & 979.2163 & 769.1398 & 765.9692 \\
\hline & $\mathrm{PF}_{\text {overall }}$ & 0.8464 & 0.9481 & 0.9522 \\
\hline & Total cost, \$/year & $514,676.09$ & $442,259.89$ & $441,643.41$ \\
\hline & Annual savings (\$/year) & - & $72,416.20$ & $73,032.68$ \\
\hline & $\mathrm{MPF}, \mathrm{kW}$ & $\begin{array}{c}10,360.30 \\
\left(\# L_{1-2}\right)\end{array}$ & $\begin{array}{c}10,347.46 \\
\left(\# L_{1-2}\right)\end{array}$ & $\begin{array}{c}10,344.84 \\
\left(\# L_{1-2}\right)\end{array}$ \\
\hline
\end{tabular}

TABLE 18: Optimal locations and kVArs of capacitors for the 119-bus system with different load models.

\begin{tabular}{lcccc}
\hline Load type & Locations and injected kVArs & Total kVAr & Method \\
\hline \multirow{2}{*}{ Industrial load } & $(50,1500) ;(41,950) ;(107,1050) ;(91,950) ;(72,1450) ;(35,1050) ;(110,1500) ;(80,1250)$ & 9700 & SOS \\
& $(80,1250) ;(32,1450) ;(50,1500) ;(96,900) ;(41,850) ;(107,1050) ;(111,1400) ;(74,1450)$ & 9850 & SQI-SOS \\
Residential load & $(74,1350) ;(111,1100) ;(52,650) ;(50,1300) ;(96,900) ;(41,950) ;(109,1150) ;(80,1250)$ & 8650 & SOS \\
& $(74,1350) ;(32,1000) ;(96,1000) ;(50,1400) ;(80,1100) ;(42,650) ;(111,1400) ;(107,1000)$ & 8900 & SQI-SOS \\
Commercial load & $(111,1450) ;(108,900) ;(6,1100) ;(81,1050) ;(58,500) ;(52,700) ;(75,1250) ;(96,600)$ & 7550 & SOS \\
& $(107,1000) ;(74,1300) ;(4,1300) ;(96,850) ;(51,750) ;(111,1400) ;(58,600) ;(80,1200)$ & 8400 & SQI-SOS \\
& $(74,1350) ;(80,1300) ;(50,1500) ;(41,950) ;(47,850) ;(91,800) ;(111,1400) ;(107,1050)$ & 9200 & SOS \\
Mixed load & $(74,1350) ;(50,1500) ;(111,1050) ;(96,900) ;(80,1200) ;(32,1400) ;(41,900) ;(108,1250)$ & 9550 & SQI-SOS \\
& &
\end{tabular}

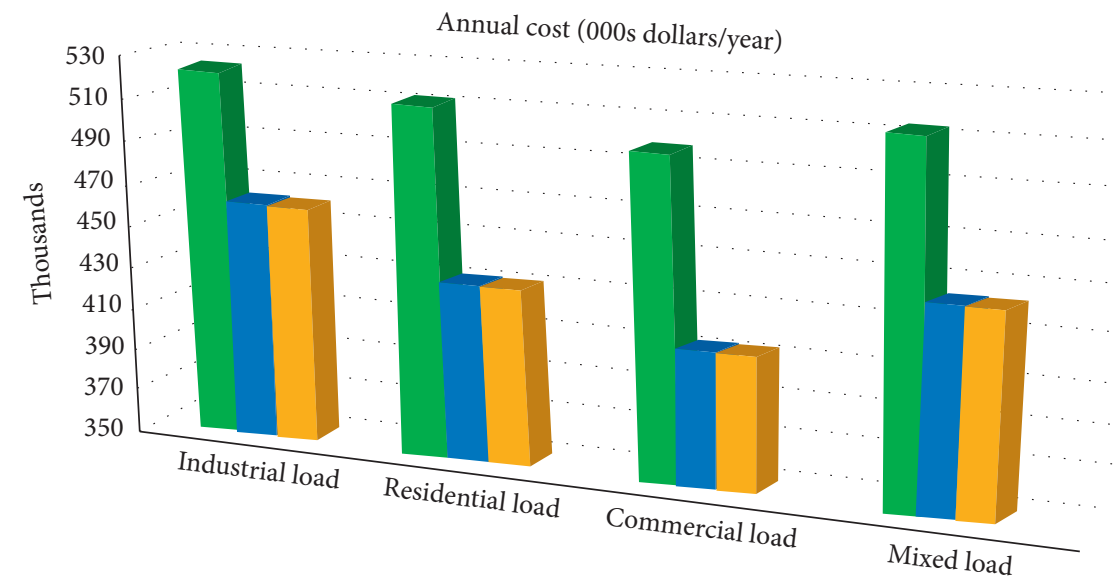

Uncompensated
- Compensated by SOS
Compensated by SQI-SOS

Figure 19: Annual cost of the 119-bus system before and after compensation with different load models. 


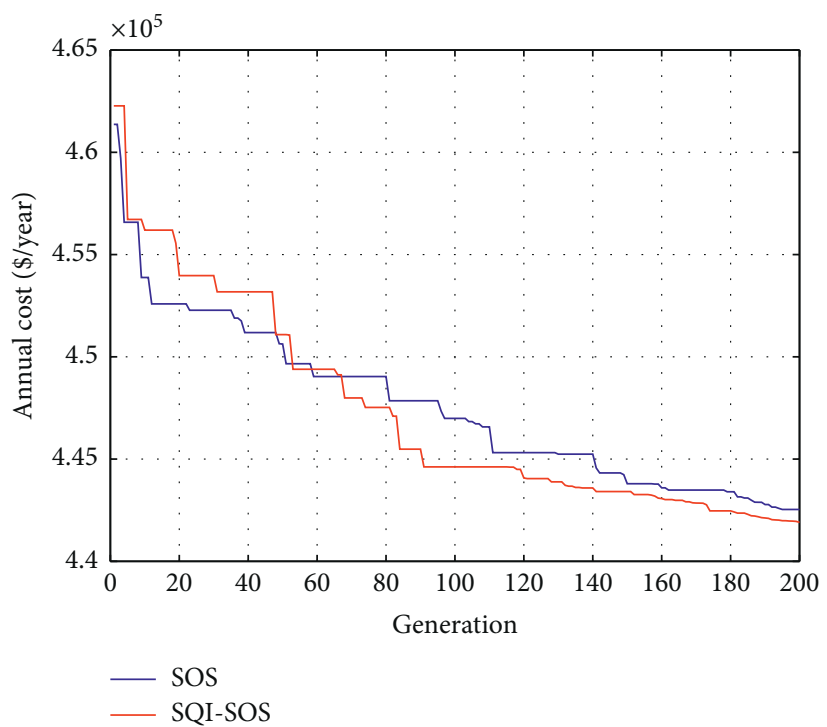

FIgURE 20: Convergence curves of the total cost of the 119-bus system with the mixed load model.

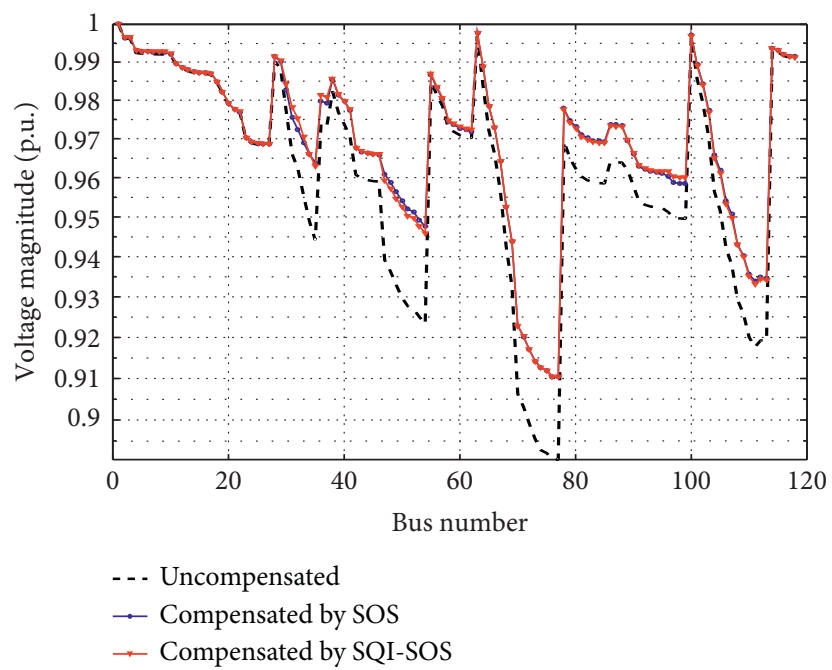

Figure 21: Voltage profile of the 119-bus system before and after compensation with the mixed load model.

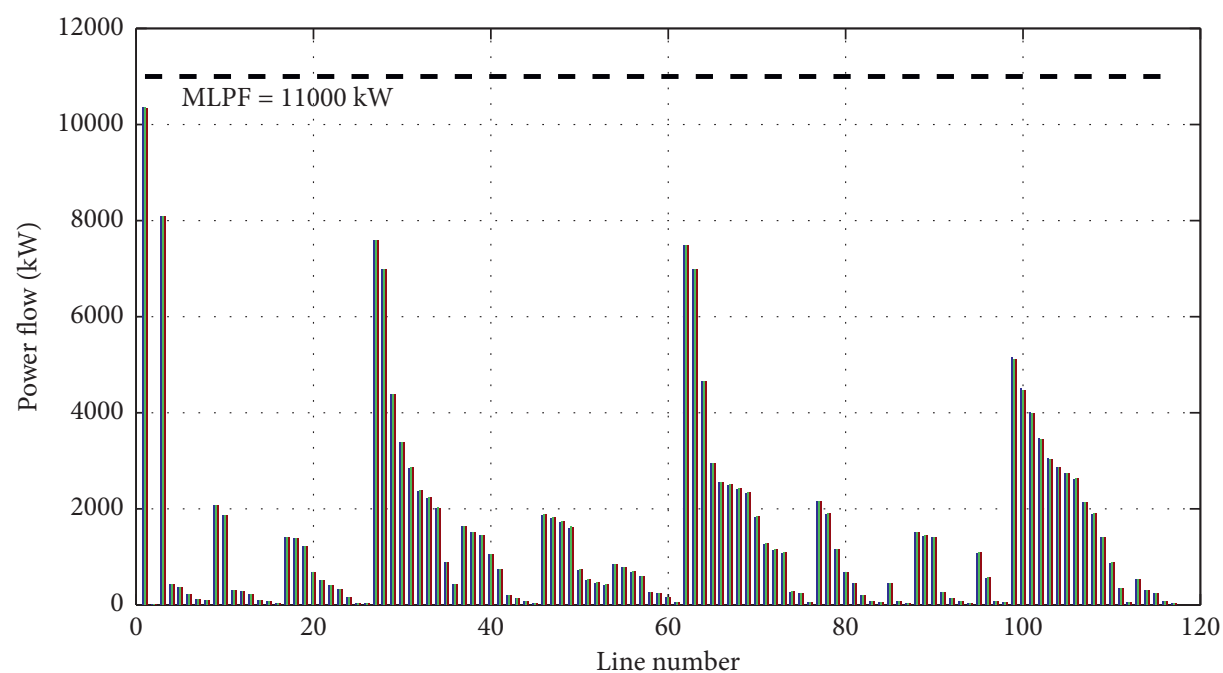

Uncompensated

Compensated by SOS

Compensated by SQI-SOS

Figure 22: Comparison of lines power flow of the 119-bus system before and after compensation with the mixed load model. 


\section{Conclusion}

In this paper, the proposed SQI-SOS has been successfully implemented for solving the OCP problem with the objective of total operating cost reduction at different load models. The proposed SQI-SOS is an improvement of the SOS method to enhance its searchability in terms of the solution quality and convergence speed. The main advantage of the SQI-SOS is that it has a simple structure with only two controllable parameters; thus, it is easy to be implemented to optimization problems. The proposed SQI-SOS has been tested on different large-scale distribution systems with 33, 69, and 119 buses. The original SOS method has also been implemented to validate the exploitation capacity of the SQISOS. The result simulations have confirmed that the convergence speed of the proposed SQI-SOS is faster than that of the conventional SOS. In addition, the SQI-SOS method has also offered a better solution quality than other compared methods such as SOS and many other methods in terms of the total annual cost. It proves that the SQI-SOS has a good performance to compete with other optimization methods in terms of the solution quality and convergence rate for the OCP problem as well as for other optimization problems in power systems. Therefore, the proposed SQISOS can be a favorable method for solving the OCP problem in distribution systems.

\section{Nomenclature}

\begin{tabular}{|c|c|}
\hline$K_{P}:$ & Energy cost per each $\mathrm{kWh}$ \\
\hline$P_{\text {loss }, i}:$ & Real power loss at any load level $i$ \\
\hline$T_{i}:$ & Duration of load level $i$ \\
\hline$K_{C}:$ & Purchase rate of the capacitor per $\mathrm{kVAr}$ \\
\hline$Q_{C, j}:$ & Size of the capacitor placed at the bus $j$ \\
\hline$K_{c i}:$ & Installation cost \\
\hline$K_{o}:$ & Operating cost \\
\hline$L:$ & Number of load levels \\
\hline$T:$ & Designed period \\
\hline CB: & Number of capacitor locations \\
\hline $\mathrm{P}_{\text {slack: }}$ & Active power of the slack bus \\
\hline$Q_{\text {slack}}:$ & Reactive power of the slack bus \\
\hline$P_{D, i}:$ & Active power demand at the $i$ th bus \\
\hline$P_{D o, i}:$ & $\begin{array}{l}\text { Active power demand operating point at the } i \text { th } \\
\text { bus }\end{array}$ \\
\hline$Q_{D, i}:$ & Reactive power demand at the $i$ th bus \\
\hline$Q_{D o, i}:$ & $\begin{array}{l}\text { Reactive power demand operating point at the } i \text { th } \\
\text { bus }\end{array}$ \\
\hline$P_{L, j}:$ & Real power loss at the $j$ th branch \\
\hline$Q_{L, j}:$ & Reactive power loss at the $j$ th branch \\
\hline$Q_{C, j}:$ & Amount of reactive power at the $j$ th bus \\
\hline$Q_{C, j}^{\min }:$ & $\begin{array}{l}\text { Minimum reactive power limit of the } \\
\text { compensated bus } j\end{array}$ \\
\hline$Q_{C, j}^{\max }:$ & $\begin{array}{l}\text { Maximum reactive power limit of the } \\
\text { compensated bus } j\end{array}$ \\
\hline$Q_{\mathrm{TC}}:$ & Total reactive power injected by capacitors \\
\hline$n_{l}:$ & Number of load buses \\
\hline$n_{b r}:$ & Total number of branches \\
\hline CB: & Number of buses where to install the capacitors \\
\hline$V_{i, \min }$ & Minimum voltage level at bus $i$ \\
\hline
\end{tabular}

$V_{i, \max }: \quad$ Maximum voltage level at bus $i$

$V_{i}: \quad$ Voltage at the $i$ th bus

$V_{o}$ : Operating point voltage

$N_{b}$ : Total number of buses of the network

$\mathrm{PF}_{k}$ : $\quad$ Power flow through the $k$ th line

$\mathrm{PF}_{k}^{\max }$ : The maximum limit of power flow through the $k$ th line

$\mathrm{PF}_{\text {overall }}$ : System overall power factor

$\mathrm{PF}_{\mathrm{min}}$ : Minimum system power factor limit at the slack bus

$\mathrm{PF}_{\text {max }}$ : Maximum system power factor limit at the slack bus.

\section{Appendix}

Detailed results of real power loss in all lines of 33-, 69-, and 119-bus test systems are tabulated in Tables 6, 10, and 16, respectively. From the tables, it can be seen that real power losses in lines are improved thanks to the installation of capacitors by the proposed SQI-SOS method.

\section{Data Availability}

No data were used to support this study.

\section{Conflicts of Interest}

The authors declare that there are no conflicts of interest regarding the publication of this paper.

\section{References}

[1] M. M. Aman, G. B. Jasmon, A. H. A. Bakar, H. Mokhlis, and M. Karimi, "Optimum shunt capacitor placement in distribution system-A review and comparative study," Renewable and Sustainable Energy Reviews, vol. 30, pp. 429-439, 2014.

[2] H. N. Ng, M. M. A. Salama, and A. Y. Chikhani, "Classification of capacitor allocation techniques," IEEE Transactions on Power Delivery, vol. 15, no. 1, pp. 387-392, 2000.

[3] H. Dura, "Optimum number, location, and size of shunt capacitors in radial distribution feeders a dynamic programming approach," IEEE Transactions on Power Apparatus and Systems, vol. PAS-87, no. 9, pp. 1769-1774, 1968.

[4] R. A. Jabr, "Optimal placement of capacitors in a radial network using conic and mixed integer linear programming," Electric Power Systems Research, vol. 78, no. 6, pp. 941-948, 2008.

[5] R. Baldick and F. F. Wu, "Efficient integer optimization algorithms for optimal coordination of capacitors and regulators," IEEE Transactions on Power Systems, vol. 5, no. 3, pp. 805-812, 1990.

[6] J. Vuletić and M. Todorovski, "Optimal capacitor placement in radial distribution systems using clustering based optimization," International Journal of Electrical Power \& Energy Systems, vol. 62, pp. 229-236, 2014.

[7] S. Segura, R. Romero, and M. J. Rider, "Efficient heuristic algorithm used for optimal capacitor placement in distribution systems," International Journal of Electrical Power \& Energy Systems, vol. 32, no. 1, pp. 71-78, 2010.

[8] M. Chis, M. M. A. Salama, and S. Jayaram, "Capacitor placement in distribution systems using heuristic search 
strategies," IEE Proceedings-Generation, Transmission and Distribution, vol. 144, no. 3, pp. 225-230, 1997.

[9] I. C. d. Silva, S. Carneiro, E. J. d. Oliveira, J. d. S. Costa, J. L. R. Pereira, and P. A. N. Garcia, "A heuristic constructive algorithm for capacitor placement on distribution systems," IEEE Transactions on Power Systems, vol. 23, no. 4, pp. 1619-1626, 2008.

[10] A. Hamouda and S. Sayah, "Optimal capacitors sizing in distribution feeders using heuristic search based node stability-indices," International Journal of Electrical Power \& Energy Systems, vol. 46, pp. 56-64, 2013.

[11] G. Levitin, A. Kalyuzhny, A. Shenkman, and M. Chertkov, "Optimal capacitor allocation in distribution systems using a genetic algorithm and a fast energy loss computation technique," IEEE Transactions on Power Delivery, vol. 15, no. 2, pp. 623-628, 2000.

[12] D. Das, "Reactive power compensation for radial distribution networks using genetic algorithm," International Journal of Electrical Power \& Energy Systems, vol. 24, no. 7, pp. 573-581, 2002.

[13] M.-R. Haghifam and O. P. Malik, "Genetic algorithm-based approach for fixed and switchable capacitors placement in distribution systems with uncertainty and time varying loads," IET Generation, Transmission \& Distribution, vol. 1, no. 2, pp. 244-252, 2007.

[14] P. Dulce Fernao, A. G. Martins, and C. H. Antunes, "A multiobjective model for VAR planning in radial distribution networks based on tabu search," IEEE Transactions on Power Systems, vol. 20, no. 2, pp. 1089-1094, 2005.

[15] S. P. Singh and A. R. Rao, "Optimal allocation of capacitors in distribution systems using particle swarm optimization," International Journal of Electrical Power \& Energy Systems, vol. 43, no. 1, pp. 1267-1275, 2012.

[16] A. A. El-fergany and A. Y. Abdelaziz, "Capacitor allocations in radial distribution networks using cuckoo search algorithm," IET Generation, Transmission \& Distribution, vol. 8, no. 2, pp. 223-232, 2014.

[17] E. S. Ali, S. M. Abd Elazim, and A. Y. Abdelaziz, "Improved harmony algorithm and power loss index for optimal locations and sizing of capacitors in radial distribution systems," International Journal of Electrical Power \& Energy Systems, vol. 80, pp. 252-263, 2016.

[18] A. Y. Abdelaziz, E. S. Ali, and S. M. Abd Elazim, "Flower pollination algorithm for optimal capacitor placement and sizing in distribution systems," Electric Power Components and Systems, vol. 44, no. 5, pp. 544-555, 2016.

[19] A. A. El-Fergany and A. Y. Abdelaziz, "Artificial bee colony algorithm to allocate fixed and switched static shunt capacitors in radial distribution networks," Electric Power Components and Systems, vol. 42, no. 5, pp. 427-438, 2014.

[20] S. Sultana and P. K. Roy, "Optimal capacitor placement in radial distribution systems using teaching learning based optimization," International Journal of Electrical Power \& Energy Systems, vol. 54, pp. 387-398, 2014.

[21] A. A. El-fergany, "Optimal capacitor allocations using evolutionary algorithms," IET Generation, Transmission \& Distribution, vol. 7, no. 6, pp. 593-601, 2013.

[22] R. S. Rao, S. V. L. Narasimham, and M. Ramalingaraju, "Optimal capacitor placement in a radial distribution system using plant growth simulation algorithm," International Journal of Electrical Power \& Energy Systems, vol. 33, no. 5, pp. 1133-1139, 2011.

[23] A. Askarzadeh, "Capacitor placement in distribution systems for power loss reduction and voltage improvement: a new methodology," IET Generation, Transmission \& Distribution, vol. 10, no. 14, pp. 3631-3638, 2016.

[24] D. B. Prakash and C. Lakshminarayana, "Optimal siting of capacitors in radial distribution network using whale optimization algorithm," Alexandria Engineering Journal, vol. 56, no. 4, pp. 499-509, 2017.

[25] A. Sharma, H. Sharma, A. Bhargava, N. Sharma, and J. C. Bansal, "Optimal placement and sizing of capacitor using Limaçon inspired spider monkey optimization algorithm," Memetic Computing, vol. 9, no. 4, pp. 311-331, 2017.

[26] M. Ayoubi, R. A. Hooshmand, and M. T. Esfahani, "Optimal capacitor placement in distorted distribution systems considering resonance constraint using multi-swarm particle swarm optimisation algorithm," IET Generation, Transmission \& Distribution, vol. 11, no. 13, pp. 3210-3221, 2017.

[27] J. Vuletić and M. Todorovski, "Optimal capacitor placement in distorted distribution networks with different load models using penalty free genetic algorithm," International Journal of Electrical Power \& Energy Systems, vol. 78, pp. 174-182, 2016.

[28] S. Das and T. Malakar, "An emission constraint capacitor placement and sizing problem in radial distribution systems using modified competitive swarm optimiser approach," International Journal of Ambient Energy, pp. 1-24, 2019.

[29] A. M. Elsayed, M. M. Mishref, and S. M. Farrag, "Optimal allocation and control of fixed and switched capacitor banks on distribution systems using grasshopper optimisation algorithm with power loss sensitivity and rough set theory," IET Generation, Transmission \& Distribution, vol. 13, no. 17, pp. 3863-3878, 2019.

[30] M. Dixit, P. Kundu, and H. R. Jariwala, "Optimal integration of shunt capacitor banks in distribution networks for assessment of techno-economic asset," Computers \& Electrical Engineering, vol. 71, pp. 331-345, 2018.

[31] M.-Y. Cheng and D. Prayogo, "Symbiotic organisms search: a new metaheuristic optimization algorithm," Computers \& Structures, vol. 139, pp. 98-112, 2014.

[32] S. Nama, A. Kumar Saha, and S. Ghosh, "A hybrid symbiosis organisms search algorithm and its application to real world problems," Memetic Computing, vol. 9, no. 3, pp. 261-280, 2017.

[33] A. K. Bohre, G. Agnihotri, and M. Dubey, "Optimal sizing and sitting of DG with load models using soft computing techniques in practical distribution system," IET Generation, Transmission \& Distribution, vol. 10, no. 11, pp. 2606-2621, 2016.

[34] D. Singh, D. Singh, and K. S. Verma, "Multiobjective optimization for DG planning with load models," IEEE Transactions on Power Systems, vol. 24, no. 1, pp. 427-436, 2009.

[35] R. D. Zimmerman, C. E. Murillo-Sánchez, and R. J. Thomas, "MATPOWER: steady-state operations, planning, and analysis tools for power systems research and education," IEEE Transactions on Power Systems, vol. 26, no. 1, pp. 12-19, 2010.

[36] M. E. Baran and F. F. Wu, "Network reconfiguration in distribution systems for loss reduction and load balancing," IEEE Transactions on Power Delivery, vol. 4, no. 2, pp. 14011407, 1989.

[37] M. E. Baran and F. F. Wu, "Optimal capacitor placement on radial distribution systems," IEEE Transactions on Power Delivery, vol. 4, no. 1, pp. 725-734, 1989.

[38] D. Zhang, Z. Fu, and L. Zhang, "An improved TS algorithm for loss-minimum reconfiguration in large-scale distribution systems," Electric Power Systems Research, vol. 77, no. 5-6, pp. 685-694, 2007. 